Illinois State University

ISU ReD: Research and eData

Theses and Dissertations

$10-25-2019$

\title{
We Can Get There: Understanding The High School Experience Of Latin@s In A Large Suburban School District
}

Octavio Rodriguez

Illinois State University, orodriguez@d211.org

Follow this and additional works at: https://ir.library.illinoisstate.edu/etd

Part of the Education Commons

\section{Recommended Citation}

Rodriguez, Octavio, "We Can Get There: Understanding The High School Experience Of Latin@s In A Large Suburban School District" (2019). Theses and Dissertations. 1189.

https://ir.library.illinoisstate.edu/etd/1189

This Dissertation is brought to you for free and open access by ISU ReD: Research and eData. It has been accepted for inclusion in Theses and Dissertations by an authorized administrator of ISU ReD: Research and eData. For more information, please contact ISUReD@ilstu.edu. 


\section{WE CAN GET THERE: UNDERSTANDING THE HIGH SCHOOL EXPERIENCE OF LATIN@S IN A LARGE SUBURBAN SCHOOL DISTRICT}

\section{OCTAVIO RODRIGUEZ}

\section{Pages}

Success in school is something that every student tries and accomplishes in different ways, but this is not a simple matter of just demonstrating academic success. Students may have the best grades, but if they do not master the "college student" (Collier, Morgan, 2004) role, many students may not succeed. When students master this role, it will help them understand the different expectations professors may have and then will be able to apply their academic skills effectively and help them meet these expectations. This is something that many students know and understand, and this information is not passed on to them from their high school teachers or counselors but from their parents, or relatives that have $1^{\text {st }}$ hand knowledge of the college student. When the student does not possess this information the chances of continuing on past high school decrease. This information I believe, can make the difference and can increase the success of Latino students no matter what school they attend. This study is significant because it aims to identify what successful practices were implemented by Latin@s within a large school district. Their personal accounts provide an understanding of what helped this small group of individuals achieved personal success and now have an opportunity to continue their education. The significance does not just have a simple effect on the district but requires a change to happen if the district is going to meet the needs of its growing Latin@ student body. 
KEYWORDS: acculturative stress; educational attainment; language barriers; socioeconomic status. 


\title{
WE CAN GET THERE: UNDERSTANDING THE HIGH SCHOOL EXPERIENCE OF LATIN@S IN A LARGE SUBURBAN SCHOOL DISTRICT
}

\author{
OCTAVIO RODRIGUEZ
}

\author{
A Dissertation Submitted in Partial \\ Fulfillment of the Requirements \\ for the Degree of \\ DOCTOR OF EDUCATION \\ School of Teaching and Learning \\ ILLINOIS STATE UNIVERSITY
}


(C) 2020 Octavio Rodriguez 


\section{WE CAN GET THERE: UNDERSTANDING THE HIGH SCHOOL EXPERIENCE OF LATIN@S IN A LARGE SUBURBAN SCHOOL DISTRICT}

OCTAVIO RODRIGUEZ

COMMITTEE MEMBERS:

Elizabeth A. Skinner, Chair

Sandra Osorio

Pauline Williams 


\section{ACKNOWLEDGMENTS}

I have been blessed with an incredible life and have experienced some remarkable events as well as experienced only shared by other minority professionals. Several years ago, I almost gave up on the most challenging journey of my life because I still had difficulties with the English language. I can write in Spanish better than I can write in English because, in high school, I was not considered as someone that would continue into college. With the help of the Latin@ student advocate and my counselor, I was able to continue my education past my high school diploma. The journey toward an EdD was personal for me because it was more about showing others who are searching for the path the importance of embracing your fears, proving your determination, and living the life each of us was intended to live. The path leading to this EdD was very much shared by many who willingly gave of their time to provide the encouragement, motivation, and ambition to help keep me going when professional and personal events drained every ounce of desire to continue. Any success which I have achieved in this effort was a shared success made possible by the relationships of supporting family, friends, coaches, and mentors that took the time to ask how I was doing. Although it is impossible to know the amount of impact and influence we might have on another person's life because of some random act of kindness that is given. I know that I could not have completed this journey without the determination that I learned from an early age and always having to depend on myself. I want to especially thank Dr. Elizabeth Skinner for working with me and spending countless hours guiding my revisions, my son's Nicholas, Danny, Joseph, and Alexander, my daughter's Lilia and Emily. My mother Angelica Lara who worked extremely hard to provide for me and my brothers and sister. My stepfather Gustavo Medina who I consider my father because he raised me after my biological father left us. Patty and Art Sternberg you believed in 
me and made me feel welcomed when others did not. Thank you to my good friend Michael Rusniak for the grammar help that you provided and for not giving up and continuing to offer your support. Thank you for walking the path with me and being there when I needed you most. I am forever grateful and hope that my children become more successful than I am. Thank you KRF for being a great friend and helping me stay focused and on task during the most difficult time in my life. You did not have to listen but you helped me believe in myself when others wanted me to fail. 


\section{CONTENTS}

Page

ACKNOWLEDGMENTS

TABLES Ni vi

CHAPTER I: INTRODUCTION TO THE STUDY 1

Research Focus Questions 3

$\begin{array}{ll}\text { Purpose of this Study } & 8\end{array}$

Significance of the Study 11

CHAPTER II: REVIEW OF TE LITERATURE 12

$\begin{array}{ll}\text { Socioeconomic Status } & 14\end{array}$

$\begin{array}{ll}\text { Educational Attainment of Parents } & 17\end{array}$

$\begin{array}{ll}\text { Growing up Bilingual } & 19\end{array}$

$\begin{array}{ll}\text { Acculturative Stress } & 21\end{array}$

Lack of Opportunity or Cultural and Social Culture $\quad 24$

$\begin{array}{ll}\text { Summary } & 28\end{array}$

CHAPTER III: RESEARCH DESIGN 29

Research Questions $\quad 29$

Research Design Procedures 30

Data Collection Protocol $\quad 32$

Data Analysis $\quad 36$

$\begin{array}{ll}\text { Participants Description } & 37\end{array}$ 
Findings in Accordance with Research Questions and Themes

Profile of Participants in the Study

Research Questions and Themes

The Definition of Success According to the Participants

Reflection

Personal Academic Success

Reflection

Student Support Systems

Reflection

Interactions with Teachers and School Staff

Reflection

Getting Help from the Experts and Planning for the Future

Reflection

Keeping Up with Important Information

Reflection

Cultural Perspective from School to School

Reflection

Different Ways to Help All Students

Reflection

Helping Students Continue their Education

Reflection 
Conclusion

CHAPTER V: ANALYSIS, RESEARCH FINDINGS, LIMITATIONS, RECOMMENDATIONS, FUTURE STUDIES, AND CONCLUSION 90

Research Findings $\quad 93$

$\begin{array}{ll}\text { Limitations } & 102\end{array}$

$\begin{array}{ll}\text { Recommendations } & 103\end{array}$

$\begin{array}{ll}\text { Future Studies } & 104\end{array}$

$\begin{array}{ll}\text { Conclusion } & 105\end{array}$

$\begin{array}{ll}\text { REFERENCES } & 109\end{array}$

APPENDIX A: RECRUITMENT EMAIL 123

$\begin{array}{ll}\text { APPENDIX B: INFORMED CONSENT } & 125\end{array}$

$\begin{array}{ll}\text { APPENDIX C: INTERVIEW QUESTIONS } & 127\end{array}$ 


\section{TABLES}

Table

Page

1. Participant Descriptions 


\section{CHAPTER I: INTRODUCTION TO THE STUDY}

It is abundantly clear that students from certain ethnic groups, most prominently African Americans and Latin@s, do not fare well in U.S. schools. It is widely documented that Black and Latin@ students generally underperform in academic areas in comparison to their white counterparts (Hollins, King, \& Hayman, 1994; Jencks \& Phillips, 1998; King, 2005). As the number of minority students continues to grow all across the United States, so has the concern for their academic achievement and success. My research focused primarily on identifying what type of support helped or facilitated Latin@s academic success within the large suburban high school district in the Midwest, where I have been a teacher for the past twenty years. For this study, the use of the "@ symbol" "Latin@" was chosen over the more frequent use of "Latina/o" as an intentional effort at gender inclusion. The participants gave me an understanding of how each individual viewed his/her own academic success and how it was different from the commonly used academic-based definition.

Most definitions of academic success often include factors such as faculty reports, advisor reports, membership in honors programs, grades, academic records, public recognition for academic achievement, timely graduation, independent scholarship, social confidence, interpersonal relationships, and increased awareness of moral issues and social problems (Anastasi, Meade, \& Schneiders, 1960; Richards, Hollands, \& Lutz, 1967; Willingham, 1985). I, however, must define what participants identified as successful in their own words and connect it to success in school. Academic achievement has been described by scholars differently in a variety of studies and has been linked to the students' grades, school involvement, and eventual attainment of a high school diploma. For this study, the above-mentioned definition related to academic factors like grade point average, rigorous class schedule, and continued participation in 
the community will not be applied precisely as was defined. The participants' explanation of success did not match with what former students viewed as their own personal success when it came to academics and school in general. The measurable academic achievement of each individual student was not something participants viewed as being significant in their personal identification of their own success. These participants did not see academic achievement by the traditional definition most commonly applied by scholars because they believed they had attained success from their perspective. Participants had to deal with personal struggles that kept them from focusing primarily on their academics. Being able to complete high school and receive a high school diploma gave them options when it came to their future education. A diploma was a symbol of meeting the state requirements and allowed them to pursue a college education and the ability to earn more money in the future. Their definition of academic success presented a different perspective that did not connect directly with what most scholars define as a success because they knew they had accomplished something that their parents had not accomplished by no fault of their own. Within the context of this study, success was established based on the requirements that had to be met by participants to be eligible for the research study. All participants met state and district requirements to obtain a high school degree, which allowed them to continue their education at any college or university of their choice. Those participants who met these requirements provided the data that help identify the factors as well as the amount of support received and given to them during their high school experience. 


\section{Research Focus Questions}

There have always been indications that Latin@ students face various struggles while trying to graduate from high school. My interest is those students who succeed despite the structural obstacles, resource inequalities, as well as various forms of racism. They represent an area of study that is lacking. The question that guided my research is: What affects Latin@ high school students' success in Northwest suburban district? To understand how these students were able to overcome such struggles, those interested in their success must realize what contributed to their success. Were these students just able to find a way to resist the dominant culture of the school, or did they become part of the dominant culture? Was there something that aided them in overcoming these struggles? What allowed them to become resilient in their environments? The resilience of those students who were able to overcome these struggles supports the importance of my research. In order to understand how they were able to overcome these struggles, I looked at resilience theory as a framework, which has its roots in psychological research that focuses on personal, family, and community-level risks to positive life development (Garmezy, Masten, \& Tellegen, 1984; Luthar, Cicchetti, \& Becker, 2000; Masten \& Powell, 2003; Rutter, 1985; Werner \& Smith, 1992). Being resilient is not a trait that only certain individuals have or do not have, and involves, thoughts, behaviors, and actions that can be learned and developed in anyone allowing them to meet challenges in their lives. Challenges and risk factors were the most common terms used when attempting to define resilience among minority students. Another study by Garza, Reyes, and Trueba (2004) offered, "Resilience is defined as the ability to confront and to resolve problems and the capacity to utilize personal or social resources to enhance limited possibilities" (p. 11). Those who research Latin@s need to understand that many factors are unique to the Latin@ population, and the use of resilience 
theory gives a critical reason for their success but does not mention all elements. However, researchers interested in explaining academic success have adopted a resilience framework to examine education and identify the factors that seem to contribute to the success of students who were identified as likely to fail (Alva, 1991; Arellano \& Padilla, 1996; Benard, 2004; Brown et al., 2001; Gonzalez \& Padilla, 1997; Henderson \& Millstein, 2003; Perez, Espinoza, Ramos, Coronado, \& Cortes, 2009). In a recent study, Phanor (2015) wrote that resilience theory, as it was initially developed, does not address the development of high expectations and academic standards as well as opportunities for participation and contribution, and has fallen short of explaining the process of resilience that takes into account academics. In the twenty years that I have been teaching, the number of students I have seen suggests an increase in the number of students who need free and reduced lunches. Each year has started with a presentation by our administration, where they present statistics demonstrating that our student population continues to require more financial assistance. District-wide, the number of students who are eligible to receive free or reduced-price lunches, live in substitute care or whose families receive public aid has increased to $36 \%$ of the student enrollment. Today's students have to be resilient because they regularly come to school hungry, do not know where they will be living or with whom they will be living for various reasons, which is out of their control. Heaton (2013) wrote that "resilience theories emphasize the contextual factors and personal resources that a person or a group uses to overcome ongoing challenges or stressors, rather than framing the struggle in terms of oppression and resistance to oppression" (p.15). Schools have always tried to help alleviate these struggles with various federally and district funded programs aimed at students who selfidentify as being in financial need. The temporary relief given to these students is only available to them, many times, while they are in school. Students will use their resilience to overcome 
these short-terms adjustments in their daily lives to continue pushing forward. Garza, Reyes, and Trueba (2004) wrote the following concerning resilience, "Resilience is defined as the ability to confront and to resolve problems and the capacity to utilize personal or social resources to enhance limited possibilities" (p. 11).

Heaton (2013) wrote that educational resilience focuses on the way the personal, social, and environmental resources available diminish the potentially adverse effects of stress factors on the students. Depending on the person, resilience can be viewed in a variety of ways. However, there is a specific feature that does appear in each case. Werner and Smith (1992) explained that while "resilience is a characteristic that varies from person to person, protective factors or mechanisms are more specific and more narrowly defined" (p. 5). Being able to identify these protective factors or mechanisms in the research will help identify the support that may help other Latin@s in the school district studied. If we cannot answer what factors contributed to foster resilience among Latin@ students, these questions will continue to affect the ability to help other students in the future. These questions represented a gap in the literature, which I have attempted to address by examining the experiences of seventeen Latin@ high school students who met the study requirements. By conducting individual interviews with these students, I tried to identify what factors contributed to their success. Understanding what factors helped these students represents an essential contribution to future research on the subject of success among the Latin@ student population. These contributions would support increased success among the number of Latin@s students enrolled in public schools currently and in the future.

To provide the best educational opportunities for the changing student demographics and provide the best services to aid them in their educational journey, understanding what works and 
what does not work must be understood by all who come in contact with these students.

Knowledge of how to help at-risk students is essential because there are still large numbers of students who do not complete high school or do not continue beyond high school.

Approximately $70 \%$ of all American high school students graduate in the expected four years, and approximately 58\% of Latin@s, 55\% of African American, and 51\% of Native Americans students graduate on time, compared to $78 \%$ of Caucasian students (Alliance for Excellent Education, 2008). When we understand what support systems help students succeed during their high school years, we can start to increase the number of Latin@s who graduate from their high schools. Graduation rates, more than anything, show the importance of identifying and getting support for Latin@s as they will continue to increase among the number of students in the United States educational system. Helping these students is not only important to me as a researcher because of the similar background we share, but according to a 2010 U.S. Department of Education report, African American and Latin@ students had the highest dropout rate of all racial/ethnic groups (Snyder \& Dillow, 2010). With proper support, these statistics can change. With our assistance, these students can be helped; however, it is first necessary to identify what has helped successful students to bring about change.

Population growth between 2000 and 2010 varied depending on the Latin@ group researched in a particular study. Latin@s, and particularly those of Mexican descent, represent the most abundant and fastest-growing ethnic minority group and the most poorly educated segment of the population (Bohon, Johnson, \& Gorman, 2006). Before going any further, there needs to be an explanation of the different types of Latin@ because we are not all the same. We have different values and beliefs. The cultural background that makes me who I am, as well as the belief that everyone can succeed when given an opportunity, requires me to try and find an 
answer to why some students can succeed academically and why some are not able to accomplish similar success. It is important to understand the diversity of Latin@ culture because of the differences that exist from one nationality to the next. Individuals that speak Spanish have been classified similarly because of the language they share. However, each country has their own cultural identity and vocabulary. Variations that exist among Latin@s may not seem important to those that do not understand how diverse we are. Administrators, teachers, school staff, and board members need to understand how this diversity can enrich the school community.

Being Mexican and eventually becoming a United States citizen, thanks to the Reagan Amnesty of 1986, I would like to know where I stand in reference to data that has been collected concerning the Mexican population and educational attainment. The population classified as being of Mexican origin increased by $54 \%$ and had the most substantial numeric change (11.2 million), growing from 20.6 million in 2000 to 31.8 million in 2010 (Bohon, Johnson, \& Gorman, 2006). Mexicans accounted for about three-quarters of the 15.2 million increase in the Hispanic population from 2000 to 2010 (Bohon, Johnson, \& Gorman, 2006). One of the other Latin@ groups closely linked with Mexicans are those individuals who come from Puerto Rico. However, Latin@s from Puerto Rico do not share all of the barriers that other Latin@s face when it comes to education in the United States, especially when it comes to higher education. The Puerto Rican population grew by $36 \%$, increasing from 3.4 million to 4.6 million. One of the other groups that have had a significant increase in its population is Cubans. The Cuban population increased by 44\%, growing from 1.2 million in 2000 to 1.8 million in 2010 . Hispanics, who reported other origins, increased by 22\%, from 10.0 million to 12.3 million (U.S. Bureau of the Census, 2010). The diversity that makes up the Latin@ population in the United 
States of America is vast and is always changing. Recognizing and understanding how these students experienced their time in high school can have a significant effect on the educational system and its ability to meet the students' needs. For this reason, I believe that the faculty, administration, and district administration needs to have Latin@s in those positions as they have a personal understanding that cannot be taken from a book or article but be part of who you are.

\section{Purpose of the Study}

The qualitative approach that I used to research what helped students during their time in their schools created a vibrant picture of their experiences during their time in one of the five Northwest Suburban High Schools. The data that was produced by those that participated in the study was in the form of their narrated experiences that identified how they were able to attain success. According to Creswell (1998), "Qualitative research is multi-method in focus, involving an interpretive, naturalistic approach in which the researcher attempts to make sense of or interpret phenomena in terms of the meanings people bring to them" (p. 15). My goal was to paint a clear picture of the experiences that were important to each participant, as each experience is different and affected each participant differently. Descriptively presenting the data allowed it to be explicative and composed of words that helped to paint pictures rather than numbers. Once complete, the reader will be able to get a clear understanding of what helped these individuals and how it could help others. That is why conducting a study of this nature required the use of a qualitative methodology, informed by phenomenology: the nuances of gender, race, class, and unique personalities, which are challenging to examine within statistical studies (Creswell, 2007). When pairing qualitative methodology with an ethnographic approach to the research, interpretation of the results allowed me to compare the participants' experiences with my own and to relate their high school struggles to those that were similar to my struggles. 
I used ethnography to understand the participants' self-reflections in order to explore anecdotal and personal experiences and connect these autobiographical stories to broader cultural, political, and social implications and understandings. Creswell (2005), wrote that ethnographic designs are "qualitative research procedures for describing, analyzing, and interpreting a culture sharing a group's shared patterns of behavior, beliefs, and language that develop over time" (p. 436).

Each interview conducted required the participants to be a former student from one of the five schools that make up the Northwest Suburban High School district. All participants were 18 years of age and were able to sign the informed consent form before the start of their interview. The seventeen participants represented each school and provided information about their experience during their time at their particular school. Their response to educationally focused questions helped identify what helped them and what could help other students in similar situations. The identification of what personal experiences and what institutional support factors were essential to Latin@ students during their time in the high school they attended provided crucial data and first-hand accounts, identifying a phenomenon that was common among participants. The identification of these phenomena did, more than anything, clarify the combination of external factors and personal experiences of these Latin@ high school graduates by including their perception of the quality and quantity of institutional support factors were available to them during their high school experience. This dissertation incorporated questions (APPENDIX C) that participants answered related to their high school experiences, allowing them to identify who helped them, what worked for them, and allowed them to be able to graduate from high school eventually. Those who participated in these interviews met my definition of what a successful student needed to demonstrate and also helped me define success based on their understanding of what success meant to them. The identification of what helped 
Latin@ students gain academic success and continue their education was at the center of my research. Future students will benefit from this research because they will have support systems already in place, as identified in the research study, to help them academically. Participants answered the same questions and answered in their own words without any guides but with the option of choosing to skip any questions that they did not feel comfortable answering.

Continuing their education beyond high school may seem like an easy task; however, Latin@students are faced with barriers that they have no control over and are born into them. The obstacles encountered by Latin@ students in schools are well documented and continue to be part of the educational landscape for these students. Research suggests that a number of risk factors contribute to the low achievement and attainment of Latin@ youth, including socioeconomic status (SES), educational attainment of parents, language barriers, acculturative stress, and lack of exposure to learning opportunities (Eamon, 2005; Garcia-Coll et al., 2002; Hoover-Dempsey et al., 2005; Prelow \& Loukas, 2003). These barriers affect Latin@ students and they were shared by a large portion of the students with whom I conducted my research. Many studies (e.g. Cabrera et al., 2000; Fisher, 1998; Pignatelli \& Pflaum, 1994; Secada et al., 1998) have examined the inadequacies of the American educational system for Latin@ students. These inadequacies keep Latin@ families from being able to fully participate in their children's education, often due to language and cultural barriers. I know that this was the main reason my mother was not able to attend many school functions and why she may have seemed like she was not interested in my education. My own experience leads me to believe that the personal connections and the development of social and cultural capital are critical for Latin@ students to overcome barriers to academic success. Latin@ students come from various Latin American countries, sharing Spanish as a common language. However the cultural diversity, language 
variation, and values are easy to put into just one category. In the literature review, I will examine the literature regarding each of these risk factors to help support my research. The data generated from these interviews will help me identify what worked for students in my district, despite these risk factors and, or barriers that a large percentage of students have in common.

\section{Significance of the Study}

This study is significant because it aims to identify what practices were implemented by successful Latin@s within a large Northwest suburban school district. Knowing what helped this small group of individuals can be used to identify what they viewed as necessary support given to them and that could be provided to other students. The significance does not just have a simple effect on the district but requires a change to happen if the district is going to meet the needs of its growing Latin@ student body. The literature review will support the need for change within the current support systems and the development of new ones aimed at providing support to Latin@ students. 


\section{CHAPTER II: REVIEW OF THE LITERATURE}

Latin@s do not fare well in U.S. schools for a variety of reasons, and the lack of research into their success motivated my research. If schools are going to help Latin@ students, they need to focus on understanding how many of these students need additional support because of the issues that are associated with them and have an impact on their learning. The research that has been conducted to this point points to a number of factors that contribute to the low academic achievement and attainment of Latin@ youth, including socioeconomic status (SES), educational attainment of parents, language barriers, acculturative stress, and lack of exposure to learning opportunities (Eamon, 2005; Garcia-Coll et al., 2002; Hoover-Dempsey et al., 2005; Prelow \& Loukas, 2003). From my experience, a large portion of the students with whom I work have been the first in their families to attain a high school education and/or beyond. Even if it may seem like common knowledge, a lack of understanding when it comes to the educational process can make the difference between the ability to succeed and fail. The literature presented supports how Latin@students have to overcome obstacles that are not obvious to anyone but themselves and how these obstacles may affect their ability to succeed in school. In today's educational environment, there is one group (Latin@s) that, because of its growth, requires that more research and attention be focused on it. Contreras, Flores-Regade, Lee, and McGuire (2011) wrote:

The international competitiveness of the United States will largely depend on the academic success of Latin@ students since the Latin@ community has experienced unprecedented demographic growth in the United States in the past five decades, yet Latin@s have experienced limited educational attainment over the past 40 years. (p. 3) 
Yosso \& Solorzano (2006) wrote about the educational pipeline, which is a system of interrelated institutions where students move from one level to the next. This journey varied from student to student and was shaped by the schools' structures, policies, and culture. The journey does have an endpoint where students who meet academic requirements can continue the educational aspirations that will take them to a high paying job. However, there are still factors that cannot be addressed by the school during this journey and are directly connected with the students that I worked with. These external factors that affect Latin@ students, and require a deeper understanding, include their socioeconomic status, parent's education level, and language barriers. Understanding how these factors affected a student when they were conducting this journey needs to be examined to understand what could better help future students. The research that follows describes how socioeconomic status, parent's educational level, and language barriers are factors contributing to Latin@'s academic achievement. When we look at a school district that is providing services to its Latin@ population and is only addressing one of these factors, we need to identify what other academic-related needs are missing. When a district, its administration, and teachers understand what factors contribute to the academic achievement of the Latin@ students they serve, they will be better prepared to help them and create a positive long-term solution for all students.

Each one of the factors may contribute to either the student's academic success or failure in the educational system of the United States. I focus on these barriers to academic success because they impact a large portion of the students with whom I work. To understand these students, educators need to know that the needs of our students have changed and that we need to change with our students. 


\section{Socioeconomic Status}

The American Psychological Association (2017) defines Socioeconomic status (SES) as

not just income but also educational attainment, financial security, and subjective perceptions of social status and social class. Socioeconomic status can include quality of life attributes as well as the opportunities and privileges afforded to people within society. The participants in this study represented a portion of the school populations that are identified as being of low-SES and received free or reduced lunch. Furthermore, the American Psychological Association (2017) wrote that poverty, specifically, is not a single factor but instead is characterized by multiple physical and psychosocial stressors. Further, SES is a consistent and reliable predictor of a vast array of outcomes across the life span, including physical and psychological health. Thus, SES is relevant to all realms of behavioral and social science, including research, practice, education, and advocacy. Understanding that these individuals are doing the best that they can and many times just being at school is a success story in itself.

This definition is essential to my research because an individual's socioeconomic status affects them from an early age and in many ways, may keep them from moving out of their current socioeconomic status. Latin@ students are disproportionately represented in lower socioeconomic status (SES) groups (American Psychological Association [APA], 2007). Their representation in lower socioeconomic status requires districts to change how they attempt to help and the types of services offered to these students. I referred to my school data for the 2017-18 school year, where $50 \%$ of the 1,907 enrolled students identified as Low-Income Students. In comparison to the rest of the Northwest suburban school district, which also had an increase from 30\% during the 2013-14 school year to its current 2017-18 Illinois report card average of 36\% district average. Reardon, Valentino, Kalogrides, Shores, \& Greenberg (2013) 
wrote that children from low-SES families enter high school with average literacy skills five years behind those of high-income students. According to Vacca (2002), a recent report by the Carnegie Corporation of New York found that more than half of the students entering high school in the 35 largest cities in the United States read at the 6th-grade level or below. By the middle grades, the majority of students may appear skillful in the mechanics of reading but are not strategic enough in their ability to explore and interpret meaning. They often go through the motions of reading and writing - saying the words or putting the words on paper. As many content-area teachers would attest, more and more of today's middle and high school students abandon reading altogether as a way of learning. The current programs offered to these students are only a temporary solution, as the district alone cannot bring these students out of their SES, which may influence the attainment of literacy skills,. The research conducted by Reardon, Valentino, Kalogrides, Shores, \& Greenberg (2013) identified a need for additional literacy programs to close the literacy skills gap that has been created. Families are not at fault for lowSES, but may remain in the situation because of the systemic and structural inequities that create gaps in the educational system that, even today, are not addressed by schools as a whole. Zwik (2012) wrote that "socioeconomic status plays an intricate role in the analysis of academic success. SES is related not only to scores on standardized admissions tests like the SAT but to performance on achievement surveys like the National Assessment of Educational Progress and other academic measures, including high school grades" (pg.29).

Jensen (2013) wrote that "when students experience poor nutrition and diminished health practices, it is harder for them to listen, concentrate, and learn. Exposure to lead correlated with poor working memory and weaker ability to link cause and effect” (pg. 28). Walker, Greenwod, Hart, \& Carta, (1994) found that children who grew up in low socioeconomic conditions 
typically have a smaller vocabulary than middle-class children, which raises the risk for academic failure. This could be because parents are not able to place their children in early childhood development classes, have books at home, or read to them. According to Bradley \& Corwyn, (2002) children from lower socioeconomic backgrounds often perform below those from higher socioeconomic backgrounds on tests of intelligence and academic achievement. These issues do not go away and later on can cause these issues to manifest themselves when taking standardized tests, which could affect their chances to attend a college or university. Reeves \& Halikias (2017) identified an educational gap when it came to recent high school graduates. The College Board's publicly available data provides data on racial composition at 50-point score intervals. College Board's estimated that in the entire country last year at most 2,200 black and 4,900 Latino test-takers scored above a 700. In comparison, roughly 48,000 whites and 52,800 Asians scored that high. The same absolute disparity persists among the highest scorers: 16,000 whites and 29,570 Asians scored above a 750, compared to only at most 1,000 blacks and 2,400 Latinos. The information showed African American students and Latin@s making up the majority of the lower scores. The Northwest Suburban High School district information presented at the start of this chapter shows that there has been an increase in the number of students classified as low-income within the district, demonstrating that the district must to get a deeper understanding of the needs of its students. The percentage of students classified as low-income varies within the five high schools that make up the district. However, because of a large number of students who are classified as coming from low-SES families has continued to grow, it has become imperative to identify and create programs that help close the gap when it comes to literacy among these students. 


\section{Educational Attainment of Parents}

Many of the Latin@s who make up 61.9\% of total Latin@s who will attain a high school diploma or higher will eventually become parents, and Murnane \& Ohls (1981) stated, "There is no better predictor of how well children will fare in school than parents' education attainment" (p. 369). In other words, parents who have higher educational attainment help their children to succeed while they are in school. A parent's higher educational attainment will help to push children to reach the same educational level, if not to exceed it. This is one of the main reasons why I am pursuing my doctoral degree. However, I also know that with this degree, I will have a chance to help more students. Students with social disadvantages, regardless of economic status, typically perform better academically when there is a positive maternal influence (Gonzales, Cauce, Friedman, \& Mason, 1996).

I know that the time that I have spent with my own children, helping them with their reading, math, and vocabulary will benefit them later on. Having to work, many times, two jobs because of the limited earning potential that is connected with a person's educational attainment will limit the amount of time spent with their children. However, having to provide for their children is their number one concern as a parent. Having to work to provide for their children is something that they must do, and in doing so, sacrifice time with their children because of the responsibilities they have to provide for their family. I personally know now, more than ever, how important my individual educational attainment has benefited my own children. They have been able to attend preschool and have had two parents who have read to them and helped them with their school work.

Scholmerich, Leyendecker, Citlak, Caspar, and Jakel (2008) noted that success on standardized tests requires a certain level of specialized knowledge embedded within the culture. 
Latin@ students must possess the vocabulary to understand the classes they are in but also make connections to what they know in Spanish if that is the primary language spoken at home. It has been shown that by the end of second grade, average children have acquired approximately 6,000 root-word meanings, but the lowest $25 \%$ have acquired only 4,000 (Biemiller, 2006).

Employment projections data shows the importance of obtaining a college degree and its connections to earning power. Individuals who earn a high school degree had median weekly earnings in 2014 of $\$ 668$ (U.S. Bureau of Labor Statistics [BLS], 2015). The research conducted by Reeves and Halikias (2017) showed how SES has a lifelong effect on the children of parents who cannot have a higher earning ability because they may not have had the exposure to the same educational experiences as other students. Mercy and Steelman (1982) argued that although different indicators of SES (family income and parents' education level) could all predict children's intelligence scores, the mother's educational attainment acted as a better predictor than the father's. Hess and Holloway (1984) were able to identify the relationship between parents and children is one of the essential variables linking socioeconomic factors to school achievement, when they integrated their results from studies of preschool, primary, and grade school children. The relationship identified by Hess and Holloway (1984) is important because early identification of students affected by socioeconomic factors can result in the implementation of support systems that will help them gain academic achievement. The Bureau of Labor Statistics (2017) showed that those who had less than a high school diploma had median usual weekly earnings of $\$ 520$ with the highest unemployment rate of $6.5 \%$. According to the information found on the United States Department of Labor site, an individual's median weekly earnings increased with a higher educational degree, while the unemployment rate decreased. According 
to these employment projections, there is a correlation between degree of education and earning potential, which is related to educational opportunities families can provide for their children.

\section{Growing up Bilingual}

The participants who provided data for my research were Latin@s who all shared the distinction of being bilingual and using both languages to communicate. Arredondo, GallardoCooper, Delgado-Romero, \& Zapata (2014) wrote that poor academic achievement among Latino students had been attributed in part, to issues of English language proficiency. The level of skill in the English language differs from one Latin@ student to the next and is different from parent to parent. Latin@ parents' own competence in the English language varied depending on the level of education they attained in their country. Most did not have a formal education in comparison to their children. Many times the parents' ability to help their children with academic requirements is not something they can correct if they did not have access to formal education due to their low-SES in their own country. Their level of proficiency between English and Spanish varied depending on factors out of their control. The connection between low-SES and language affects both the students and parents because parents have different levels of education, which limits their English language proficiency, which in turn affects their earning power and their ability to enroll their children in preschool programs. Having to provide for their children limits the amount of time they have to spend reading to their children, which is essential when it comes to language proficiency. Parents who are always working because they are providing for their children may impact their children's language proficiency in both English and Spanish. Stromquist (2011) wrote that the low levels of academic success that exist among Latin@ students come from a variety of socio-cultural reasons, which, for the most part, are still prominent in our diverse society, which include language barriers, school family communication 
barriers, and oppression and discrimination. Language and culture were two characteristics that had a deep connection with the participants in my study, but we need to look at them as internal. If one does not understand the relationships that exist, there could be a disconnection, and these students may be seen as not following the norms. Gaitan (2012) wrote that" this is demonstrated in the ways students speak to their peers and their teachers; it is how the teacher asks questions of the students" (p. 308). When teachers do not understand the cultural differences that exist among their students, the teachers are not able to help their students. Latin@ students, I believe, more than any other student, have to overcome the association/classifications that they are all the same, and that what works for one works for all. As I mentioned earlier, Latin@ students share a language but do not share the exact language, nor do they share a specific culture. RodriguezValls' (2009) research showed that students' academic growth was heightened when the teachers used two key factors: students' native tongue and references to students' native culture.

Many studies (e.g., Cabrera et al., 2000; Fisher, 1998; Pignatelli \& Pflaum, 1994; Secada et al., 1998) have examined the inadequacies of the American educational system for Latin@ students. Gándara and Contreras (2009) stated, "While critics in the United States claim that bilingual education is a 'failed experiment,' most other modern nations consider it the norm and cannot imagine why Americans would prefer education in only one language"(p. 128). Over the years, I have had students who took part in dual language programs, and they were by far some of the most advanced students I have had the privilege of teaching. The number of students has declined, as many of the programs have been terminated for various reasons, but the few students who came from these dual language programs are still stronger academically than those who did not participate in the program. Among other inadequacies, language and cultural barriers within the educational system of the United States keep Latin@ families from being able to fully 
participate in their children's education. To concentrate on providing for their families by working two jobs, parents cannot attend as many school functions due to their schedule. The parents' language proficiency may keep them from being able to support their children when they are away from school because they may not know what is going on, particularly if all the information the parents receive is not in the language they understand. Parental involvement provides support to the school and helps keep students on track. As a parent of six children, I receive information provided by their teachers, which helps me identify ways that I can help them not fall behind in a particular class. Ramirez (2003) analyzed the benefits of Latin@ parental involvement in their children's education and found benefits from their participation, such as sustained gains in academic achievement, enhanced English language skills, increased student cognitive growth, improved student behavior in school, and enhanced home-school relationships. If the schools are not meeting the needs of their students, there is an even bigger problem in the future for not only Latin@s but also for the United States.

\section{Acculturative Stress}

Understanding that not all Latin@s in the U.S. come from the same country but rather from various countries where Spanish is spoken and cultural practices are different, is essential in helping students learn. Being different from others causes stress that can keep students from reaching a higher academic level than those students who are not classified as Latin@. Adelman andTaylor (2015) wrote that there are other factors causing stress, which include intergenerational conflict and psychological reactance to parental guidance which may appear as a youngster identifies with the peer culture at school and with what is learned from the school curriculum. Being in a new school is hard enough, but when you add other potential stressors that individual students may feel, their stress level will increase. As Qin (2009) stresses, 
immigrant children and youth must traverse multiple cultural worlds "and the often conflicting expectations they face in daily life. Many are torn between the attachment to their parents' culture, the lure of the adolescent peer culture, and aspirations to join the American mainstream culture" (p. 37). During the interviews, participants expressed their sense of belonging because of the connections they had made with a trusted adult. This made a massive difference for them, and they showed it during the conversations that we had. Students moving from junior high school to one of the five Northwest Suburban High Schools had to deal with the new educational setting, staff, and new students that created acculturative stress. Stress that is related to the specific process of acculturation is referred to as acculturative stress (Balls-Organista, Organista, \& Kurasaki, 2003). Berry (2003) defined acculturative stress as "a stress reaction to challenging life events that are rooted in the experience of acculturation" (p. 31).

Anyone that comes to a new country and is thrown into the middle of that culture will experience shock because of the differences that exist between what they are used to and what their new environment has as its norms. This term was initially conceptualized as "culture shock" (Berry, 2006, p. 287). Latin@s living In the United States experience this culture shock, which can be used interchangeably with the term bicultural stress. Romero, Marinez, and Carvajal (2007) described bicultural stress as "the perception of stress due to everyday life stressors that result from the pressure to adopt the majority culture as well as the minority cultures for youth in multiethnic environments" (p. 446). This definition reflects that there are pressures to adapt to the new culture that every new school has when you first step through its doors. The dominant culture of each school maintains the school's culture, and passes it to the incoming class of freshmen each year. Latin@ have to attempt to maintain their own cultural heritage while adapting to this new school culture. A student's immigration status can also have an effect on 
Latin@ students because they may see their time in high school as a temporary situation. Today, more than ever, they may not have the option of continuing their education. The student's immigration status can also become a stressor as it was for me before I became a United States citizen. As Romero, Carvajal, Valle, and Orduña (2007) wrote, "discrimination, negative stereotypes, intergenerational acculturation gaps, and pressure to speak multiple languages" (p. 520) are examples of stressors that create bicultural stress for the Latin@ students and individuals. If Latin@s experience any of the stressors mentioned above, they experience acculturative stress. Berry (2006) wrote that when individuals experience this type of acculturative stress, "they come to understand that they are facing problems resulting from intercultural contact that cannot be dealt with easily or quickly by simply adjusting or assimilating to them" (Berry, 2006, p. 294).

Acculturative stress according to what Berry describes is not something that individuals can simply adjust to and is something that easily or quickly. Latin@ students have to do their best to become part of the dominant school culture and keep their own cultural identity separate until they are asked about their culture. Being able to separate from one's cultural identity seems like an ultimatum when trying to become part of a new culture. This will require an individualized adjustment when it comes to dealing with the dominant host culture. Smokowski \& Bacallao (2008) identified biculturalism as a way to cope with acculturative stress, where one preserves his or her ethnic identity and creates a positive and constructive relationship with the new dominant cultural group. Latin@s in the United States have to try and fit into the dominant culture, as well as the school environment in which they will participate, if they are to get ahead. There have been few studies that have examined the role that schools have when it comes to acculturative stress among Latin@ students. This is something that my work examined more 
closely with the students who I interviewed. This is of concern because schools are the gateway to American society for many immigrants and other ethnic minority youth (Olsen, 1997). For many of these students, schools are the one connection to the mainstream American way of life.

\section{Lack of Opportunity or Cultural and Social Culture}

Latin@s who come to the United States do not have institutional memories and need to be taught how institutions, including schools, function in this country. Many Latin@ students do not have a family member who can teach them, through institutional memories, how to prepare for and access higher education. Bourdieu (1986) wrote that cultural capital refers to the rules and values an individual learns as a child in the family of origin. Latin@ students bring their norms and values to the schools they attend, believing that they are important. Senge (2000) wrote, "a school's culture is its most enduring aspect. An administrator may be able to change the rules of the school, but cannot tell the staff to "change their culture" (p. 324). I found this interesting because all the participants who I interviewed expressed how they had a trusted adult who made them feel welcomed.

Similarly, when I was attending these schools and experiencing the school culture, I found that it was hard to explain to my parents when they would ask about pep rallies or other school events that make up the culture of the school. My cultural capital was different from that of other students, in that most students had parents, aunts, and uncles who had attended college and could help them navigate their way towards college life. Bourdieu (1984) explained the concept of inherited cultural capital and acquired capital and shows the importance that cultural capital has on the success of individual students. According to Bourdieu (1984), the educational system's primary role is that of cultural reproduction. In many ways, this has been the reproduction of the culture of the dominant classes. There has been a change in student 
demographics within all of the five Northwest Suburban High Schools, yet the school's culture has not changed to reflect the students they serve. Yosso (2005) wrote that according to Bourdieu "In other words, cultural capital is not just inherited or possessed by the middle class, but rather it refers to an accumulation of specific forms of knowledge, skills, and abilities that are valued by privileged groups in society" (p. 8). The possession of cultural capital varies with social class, yet the education system assumes the ownership of cultural capital is the same, regardless of one's social class. I believe in and have used education as a vehicle to improve my own SES, social class, and cultural capital and see how important having all three have been to my way of life. I now possess what the dominant culture has in the form of cultural capital and an understanding to better guide my students and my own children when it comes to education. Bourdieu (1984) refers to the possession or sharing of this dominant culture as cultural capital. Latin@ students may not have a direct connection with the dominant culture because they may only experience this dominant culture at school.

The cultural capital that the dominant class possesses as the result of personal experience helps their children in the form of guidance and helps them continue their education. Parents possess this cultural capital because of their experiences, and this information was then passed on to their children and or family members. Those individuals who had a family member attend a university would have this information because this was part of their family culture and history. Having worked in the same school for the past 20 years, I have had many conversations with Latin@ students who praised the support of the fantastic staff that helped them. They took the information that was given to them and helped them transition into higher education because they added to their cultural capital. 
Nunez (2009) found that when students perceived that the faculty was interested in them, the students had a stronger sense of belonging, which Nunez explained was a type of social capital that added to their students' chances for success. Social capital for Latin@s, in many ways, requires them to put their social ideas aside and accept the social ideas of their schools. The social ideas of Latin@ students may be different from those of the schools because of cultural and linguistic differences. In the Northwest Suburban High School district, the social ideas and systems have continued even with the increased number of minority students who call these schools their own. Social interaction within the school is significant to all students because this is where students meet and gain information from the interactions they have every day. Students that receive important support from these interactions can apply them to their educational aspirations. While interacting socially, these students may add to their social capital. The role of social capital when it comes to Latin@ students allows them to assimilate with the school's social expectations and ideas. Cultural capital, when it comes to Latin@s, can be connected with struggles that Latin@ students must deal with during the high school experience including SES, educational attainment of their parents, language, acculturative stress, and lack of exposure to opportunities. The students' ability to add social and cultural capital while they are at school in the form of academic vocabulary related to higher education and cultural capital in the form of expecting to take college classes allowed them to grow in both areas. Coleman (1988) argued that "social capital is defined by its function. It is not a single entity but a variety of different entities, with two elements in common: they all consist of some aspect of social structures, and they facilitate certain actions of actors-whether persons or corporate actors-within the structure" (p.S98). Like other forms of capital, social capital allows the production of outcomes, which would otherwise not be possible. I can only speak from personal experience, 
but I never had anyone in my family talk about what college I was going to attend, mainly because just about all my family members never reached or even graduated the equivalence of high school in Mexico. Lack of Social capital places Latin@ students at a disadvantage because if they do not have family members who attended college, Latin@s may not have the same expectations as those who had family members in college. Students who have a family member who has a college education will receive benefits, in the form of information, from him or her, thus accumulating greater social and cultural capital. Coleman (1988) also writes about networks that, as families, work on behalf of the members of the network to help all members reach their goals.

When we talk about Latin@ students, we need to realize that Latin@s are not all the same just because of the language that they speak. Latin@s do not all come from the same cultural backgrounds, nor do they all have the same traditions and customs. Many speak different forms of Spanish, and depending on the country, they come from the meaning of certain Spanish words change in meaning and how they are used. There are complex layers to the definition of the word "Latin@." Some of these layers unite all Spanish-speaking individuals, while other layers demonstrate the diversity within the community. Those who identify with this word come from different countries, have different cultural traditions, and practice different customs. The vocabulary differences that exist among the countries impact everything from social interactions to cultural practices. After twenty years teaching the Spanish language, and because of the various discussions that I have had with students from various Latin American countries, my vocabulary has increased greatly. I understand the cultural practices of various Latin@ cultures and can relate to those students better. 


\section{Summary}

The study intended to show how, despite various hurdles described above, including socioeconomic status (SES), educational attainment of parents, language, acculturative stress, and lack of exposure to learning opportunities, some of the Latin@s in the Northwest Suburban High School district were able to succeed. A description of the social and cultural capital connections that students made during their high school experience can help those interested in understanding the diversity that exists among the Latin@ population and result in more services to help them. The benefits for the district, educational system, and the teachers include gaining the necessary understanding to support Latin@ students more effectively. Each school can support Latin@ students by looking at the students' cultural backgrounds and attempt to understand how diverse cultural backgrounds can better blend with the school's culture and by recognizing the characteristics that other students possessed that helped them succeed in school. Also, understanding that each Latin@ student is affected by not only the language differences, but also by the personal interactions they may have with school staff, is something that can help determine support services for them. I expect that the school district will listen to the voices of these former students who participated in the study and learn what will better serve the Latin@ students walking their hallways. 


\section{CHAPTER III: RESEARCH DESIGN}

Understanding success among Latin@ students in my school district was the driving force behind my research. In an attempt to make an accurate representation of the services and support systems offered to the Latin@ students attending the five Northwest Suburban District high schools, every effort was made to get two students at a minimum from each school, one female and the other male. I received more cooperation from some schools than from others, and this limited the number of participants who took part in the study. I contacted these former students to ask for participation in the research study. Selecting former students to participate in the study offered a small picture of what services and support were provided to them during their high school experience.

Students who participated in the study answered questions that directly connected with their success in school. In an effort to identify what helped participants gain academic success, I asked participants to answer the following ten questions:

1. How would you describe success in your own words?

2. Do you believe that you were successful during your high school career?

3. What positive and negative views or experiences stand out during your education in the American school you attended?

4. What type of experiences or relationships did you have with your teachers in the school you attended? Can you explain the role that your teachers played in developing their future academic choices?

5. During your high school career, how many times did you meet with a counselor? During these meetings, how often did you receive information that was important and helpful to you for continuing your education? 
6. How often did the school provide current information about your individual academic progress, and how well did the school help you to understand and to practice strategies for academic success?

7. How informative and supportive were the counselors at your school, especially with regard to college entrance requirements (i.e., grade requirements, test preparation, the application process, and admissions practices)?

8. From your perspective, how supportive was the school of your heritage and cultural background? In what ways were your heritage and cultural background incorporated into the school's educational mission?

9. What types of academic support did the school provide to assist with your continuing education? In your view, what kinds of academic support did the school lack?

10. In your experience, what effect did the academic and cultural support system at your school have on your academic success?

\section{Research Design Procedures}

I used a qualitative research approach for my study that would allow me to get the participants' responses to the above questions. Understanding how recent high school graduates understood success was essential to my research. Their views on what helped them and what support was given to them during their high school experience can be used to help future students. According to Creswell (2005), qualitative research is "a type of educational research in which the researcher relies on the views of participants, asks broad, general questions, collects data consisting largely of words (or text) from participants, describes and analyzes these words for themes, and conducts the inquiry in a subjective, biased manner" (p. 39). A qualitative approach allowed me to provide the viewpoints of Latin@ students regarding their own 
perceptions of support they received during their high school experience and how that affected their ability to graduate. The responses that were given by the recent graduates provided critical information that can be used to help other students who have similar backgrounds. Ethnography is a type of qualitative research and I wanted to use an ethnographic approach to understanding the participants' perspective when it came to their own experiences during high school. Based on the work of Wiersma (1995), this study qualifies as ethnographic research in which a problem is studied from a cultural and ethnic point of view. Participants made up an essential ethnic group that cannot be ignored and requires additional support in schools. An ethnographic approach helped to identify areas where support was lacking. The participants' cultural and ethnic point of view was crucial to the overall understanding of what helped these students achieve personal success "The term ethnography refers both to a research process and the product of that process" (Wiersma, 1995, p. 249). During the four years that I was able to get to know some of the participants as students, I would ask them about how they were doing, and we would talk about what they wanted to do after high school. According to Madison (2005), in ethnographic studies, researchers study a cultural group or particular phenomenon in a naturalistic setting, using primarily observational data to gather information over a period of time. According to Creswell (1998), "qualitative research is multi-method in focus, involving an interpretive, naturalistic approach in which the researcher attempts to make sense of or interpret phenomena in terms of the meanings people bring to them" (p. 15). This is one reason why I incorporated a qualitative research approach to provide an understanding after looking closely at a person's words, actions, and records. Glesne (2011) stated that "qualitative studies are best at contributing to a greater understanding of perceptions, attitudes, and processes" (p. 39). It is crucial to understand the perception that Latin@ students have in regards to the support given to 
them while completing their high school education. The participants' own words help one understand how the processes they completed helped them and what may be needed.

As Hammersley (1985) stated, "the task [of ethnographers] is to document the culture, the perspectives and practices of the people in these settings. The aim is to 'get inside' the way each group of people sees the world" (p152). Working with students during the past twenty years I have been able to observe, support, and guide Latin@ students through their educational journey in a Northwest suburban school. According to the definition of ethnography my twenty years of fieldwork or the active and prolonged involvement with the Latin@ population within the school I work in meet the definition of being an ethnographer. The social phenomenon that I have been able to observe, and can relate personally, helped me develop the research questions for the study. The participants responses to these questions generated further insight into the overall success of the participants, and offered explanations for the academic success of this group of Latin@ students.

As Merriam (2009) states, "The second characteristic of all forms of qualitative research is that the researcher is the primary instrument for data collection and analysis. Since understanding is the goal of this research, the human instrument, which can immediately be responsive and adaptive, would seem to be the ideal means of collecting and analyzing data" (p.15). Being able to talk with participants before I asked them the interview questions created a relaxed environment where participants could answer honestly. The goal of the interviews was to present the participant's story in a way that captivated the reader.

\section{Data Collection Protocol}

Participants for this study had to meet specific requirements before they could be identified and contacted by teachers, counselors, and other staff members within the school 
district. Before I started contacting prospective participants, I had a meeting with my school's principal, where I explained the purpose of the research and what I was investigating. The principal then presented the information at the next school board meeting to request formal permission from the school board so that I may contact former students. I was given permission after the board meeting and received a written letter from the principal confirming the approval of the research. After the final IRB filing requirement was completed, I sent out a request to a counselor at each of the high schools and to teachers who I knew worked with Latin@ students, requesting contact information for students that had recently graduated. I received the names and contact information for those students who met the IRB requirements and proceeded to contact each former student individually. I wanted to get as many former students as possible to get a good representation of the district.

In order to better contextualize the data that was generated, I wanted to get representation from all the schools. The ability to use multiple perspectives from various participants was essential, and that is the main reason why participants from each school were required. I sent an email request to representatives from all the five Northwest Suburban High Schools within the district, inviting them to participate in the research study (APPENDIX A). Those participants who replied to my email inquiry were asked to provide me with a time and a location where they would like to complete the interview. I was able to travel for some of the students, as they were not able to meet me because of distance or lack of access to a vehicle. Once we met at the selected time and location, participants were asked to read the consent form after talking with them about how they were doing currently in school. After reading the consent form, the participant was asked to sign the form to start the interview process (APPENDIX B). I also informed students that I would be recording the interview in order to have an accurate reply to 
each of the questions. I explained to them that the recordings would be deleted once they had been transcribed, and only the transcriptions would be used in my research. I read the consent form along with them, letting them know that they did not have to answer all questions if they did not want to answer any of the items. I then created a sample recording to make sure that the audio recording would be clear and easy to understand. I allowed participants to listen to the test recording, deleting it after participants had listened to it. I then proceeded to ask participants to let me know when they were ready to begin the interview. When participants told me they were prepared to start the interview, I started the recording and proceeded to ask each of the questions in order (APPENDIX C). I waited after each response, and before continuing, I would ask them if that was all they wanted to say. I kept this process for all ten questions, and after I was done with all of them, I thanked them for participating in the study. Each interview lasted between ten and fifteen minutes. During the interviews, I kept field notes that helped me create the participants' table of the necessary information that helped me organize and connect their responses to the questions. I kept field notes before and after the interview process that helped me create a summary for each participant, using pseudonyms to protect their identity (Table 1).

The questions focused on three different areas of interest. Questions one through three asked students to speak about what their idea of success was and how they achieved it during their time in high school. Questions four through seven invited participants to identify what support factored in helping them during their high school experience. Questions eight through ten asked them to provide information on programs aimed at assisting Latin@ students during their high school experience (APPENDIX C). The semi-structured format of the interview allowed participants to answer questions honestly and in a similar fashion. Weis and Fine (2000) highlighted the importance of ethical research by emphasizing the degree of care that must be 
taken to identify and eliminate any potential issues that may arise (actual or perceived) where power between the researchers and the participant can be abused. Participants were told from the start that they could choose to answer the questions that they felt comfortable with and could choose not to answer those they felt uncomfortable answering. The importance of voluntary participation in the study was emphasized at the start of each interview so that each participant understood and knew they provided only the information they were willing to share. In order to ensure the protection from any potential of physical or mental harm to the participant, safeguards were established for every phase of this study.

After I completed the interview with each participant, I proceeded to transcribe their interviews and using the field notes, I was able to create table 1 that allowed me to keep each participant's information organized and easy to access. The participants provided their own accounts of their experiences, and I was able to identify similar beliefs about their experiences. The participants' responses to the questions were used during data analysis to identify themes they experienced during their high school careers. The criterion-based sample of participants allowed me to get representatives from the five high schools that make up the district and create a representation of what it was like for them. Creswell (2007) wrote that criterion sampling is the most effective method of sampling for phenomenological research, as it is narrow and ensures that all individuals have experienced the phenomenon. Understanding the events they experienced created valid information that will be used to make recommendations on how to better serve Latin@ students within the district. Seidman (2005) explained that "If the goal is to understand the meaning people involved in education make of their experience, then interviewing provides a necessary, if not always wholly sufficient, avenue of inquiry. 
Interviewing provides access to the context of people's behavior and thereby provides a way for researchers to understand the meaning of that behavior" (p. 11).

\section{Data Analysis}

I organized the information according to what Miles and Huberman (1994)

recommended, arranging events and experiences by successive time periods, sorting them into several categories. This helped me identify similar responses and or phenomenon to each question asked during the interview process. The NVivo software program allowed me to code all participants' own words and phrases in order to determine categories that would help me organize the data while at the same time searching out possible patterns and similarities. The program analyzed the frequency of similar phrases being used by participants. I used the table of participants to identify the most common phrases used by the participants and then included those as part of my analysis. The table helped me organize all participants' replies in order to help support a common theme for each of the ten questions they were asked to answer during the interview. The result was thematic answers to each question with similar connections and understanding by each participant that helped me choose those that had the most significance and were connected. Creswell (2013) claims that the coding of qualitative data is a judgment call, impacted by the philosophical assumptions of the researcher and the theoretical framework that is guiding the inquiry. The identification of similar themes and understandings of each participant showed how even after almost twenty-six years, their views on education and success are identical to my own when I was a Latin@ high school student in a similar school district. The common themes that were identified from each of the participant's interviews allowed me to group the ten questions within those common themes. The comparison and analysis of each question helped me identify the most critical beliefs among the participants. Clandinin (2013) 
claimed that narrative analysis begins with an understanding of the term narrative. Each interview and the organization of each question helped me explore each participants' knowledge of their high school experiences. The goal was to ask participants questions that build on each other to keep them focused on a common theme. Participants shared their experiences as they saw them, and my goal was to capture those experiences and then make connections between all participants. According to Clandinin (2013) in historical research, participants share their experiences in a manner that positions events and characters in a time and space to make meaning of the lived experiences within the context of the phenomena under investigation. In the narrative analysis, there is a reading and re-reading of each participant's interview transcripts to organize data into chronological order. A similar study conducted by Sanchez (2013) combined narrative analysis with Creswell's (2013) steps for analyzing and interpreting participant's data by organizing the data, transcribing the da ta, exploring the data, and coding the data.

\section{Participant Description}

Table 1 Participants

\begin{tabular}{|l|l|l|l|l|}
\hline Pseudonym & Age & Date of Interview & Gender & College Status \\
\hline Mario & 18 & $5 / 18 / 2017$ & M & Freshmen \\
\hline Andrea & 19 & $5 / 18 / 2017$ & F & Freshmen \\
\hline Juan & 18 & $5 / 19 / 2017$ & M & Freshmen \\
\hline Raul & 19 & $5 / 19 / 2017$ & M & Freshmen \\
\hline Juanita & 18 & $5 / 19 / 2017$ & F & Freshmen \\
\hline
\end{tabular}

(Table continues) 
Table 1, Continued

\begin{tabular}{|l|l|l|l|l|}
\hline Pseudonym & Age & Date of Interview & Gender & College Status \\
\hline Ernesto & 19 & $5 / 20 / 2017$ & M & Freshmen \\
\hline Juanes & 19 & $5 / 20 / 2017$ & M & Freshmen \\
\hline Teresa & 19 & $5 / 26 / 2017$ & F & Freshmen \\
\hline Irma & 19 & $5 / 26 / 2017$ & F & Freshmen \\
\hline Carlos & 19 & $6 / 13 / 2017$ & M & Freshmen \\
\hline Amanda & 19 & $6 / 13 / 2017$ & F & Freshmen \\
\hline Elena & 18 & $6 / 13 / 2017$ & F & Freshmen \\
\hline Andres & 19 & $7 / 31 / 2017$ & M & Freshmen \\
\hline Alberto & 19 & $7 / 31 / 2017$ & M & Freshmen \\
\hline Juana & 19 & $9 / 16 / 2017$ & F & Freshmen \\
\hline Susana & 19 & $9 / 16 / 2017$ & F & Freshmen \\
\hline
\end{tabular}

The participants in this study included seventeen recently graduated former students from each of the five schools making up the district. Eight of the participants were male, and nine of the participants were female and all were at least 18 years of age, thus meeting IRB requirements. Seven out of the seventeen participants were taking summer school classes as of September 16, 2017, which was when the last interview was conducted.

Within this chapter, I described the rationale for using a qualitative research design and and ethnographic approach to analysis for the purpose of examining the personal experiences of seventeen Latin@ students in order to understand what support systems they used to achieve success. The description of my role as a researcher is included. The selection of the participants 
was aided by a trusted adult, school counselor, and administrator that had developed a connection with participants. The trust developed with these individuals allowed participants to sit down with me and complete their interview. The data transcripts generated from the interviews were then used to write a summary of the participants' experiences, using some of the participants' own words to support my analysis for that particular question. The participants that completed the interviews were all eager to share their own personal experiences and tell their own story of success. Each meeting with a participant allowed me to self-reflect on my own personal experiences when I was a high school student, and, on various occasions, I was able to share my own experiences with participants after each of their interviews were completed. In doing this, I believe that our shared experiences and interactions showed them how important the information they provided was to my research and how they could bring about change. 


\section{CHAPTER IV: RESEARCH RESULTS}

In this chapter, I report the results and research findings from my exploration of the high school experiences of Latin@ students recently graduated from one of the five high schools in the Northwest Suburban School District where I teach. Within this chapter, the information provided is divided into the following sections: participants' identification of success, participants' interactions with school personnel, academic feedback given by the school, and the school support of the students cultural differences. The primary data collected from participants was from their interview, which resulted in the emergence and then creation of themes related to each of the ten questions. The participants were members of the fastest-growing minority group within the district over the last five years, according to the state of Illinois report card. By exploring the participants' families' background characteristics, their experiences, and identified support factors, several themes emerged, which shed light on what support they identified as being relevant to them and their success. The seventeen participants represented all of the five schools within the Northwest Suburban High School district and shared similar experiences during the time they attended the schools.

\section{Findings in Accordance with Research Questions and Themes}

Based on the research findings, the creation of a personalized narrative, connecting multiple experiences, demonstrated what participants identified as helpful. These personal narratives painted a picture of what each participant experienced during their high school career. All participants had their own story but shared a similar cultural, linguistic, and economic backgrounds that required them to seek help in a variety of ways. All participants showed a level of resilience that was unique and helped them overcome some of the obstacles described in chapter 2 . The participants' capacity to develop resilience continued to grow over time with the 
help of the support systems that allowed each participant to overcome the obstacles Latin@ students often face. These obstacles connected the participants in this study, and their development of resilience helped them graduate from high school and have the opportunities to continue their education. I found that the explanation given by Gonzalez and Padilla (1997) ran parallel with the experiences of the participants who I interviewed because each participant, by just being a minority Latin@ student, was at risk for failure. Gonzalez and Padilla (1997) explained, "Resilience offers a new perspective from which to view academic achievement; rather than focusing on the shortcomings of students who are at risk of failure, the resilience construct attempts to identify the factors that account for success" (p. 315). Each participant provided me with examples of how they demonstrated resilience to overcome factors that affected his/her everyday life as a student. The descriptive summary that was created based on each of the participant's educational experiences while being a student in the Northwest Suburban High School district helped to identify the factors that accounted for their success. Their narratives also helped identify areas of need that should be addressed if more Latin@ students are going to achieve success within the academic definition of the word. Their narratives were essential in representing what a Latin@ students deal with when attending one of the five schools within the school district. I found that participants were able to use their own words to express how they felt and what they believed helped them continue to have resilience each year. Heaton (2013) wrote that the construct of resilience was useful in explaining the resources and strategies that students accessed to avoid the pitfalls and stresses that go along with being a student of color in the schools they attend. Because they were resilient, they were able to conform to the system enough to achieve high levels of personal academic success. The interviews that were conducted also showed how these former students continued to be resilient 
through their ability to form a positive relationship with an adult and being able to share their experiences. Placing participants' personal narratives alongside each other allowed me to compare their experiences and identify themes for the majority of the seventeen participants.

\section{Profile of Participants in the Study}

Mario was a recent graduate of the high school where I teach and was the first participant I interviewed. I had the privilege of attending his graduation, and he was excited to have graduated and was preparing to take a couple of summer school classes at William Rainey Harper College. I have known Mario since his freshman year in high school as both his teacher and mentor. I had built a great relationship with him and his family, and he wanted to be the first person I interviewed for my research. He was involved in multiple school sports, activities, and clubs. Mario stated that he was looking forward to his 1st year of college classes.

Andrea had been part of a mentoring program at the school where I teach for students interested in education as a career. She was a senior when she completed the mentoring program with me and had previously been a student in my Heritage Spanish speaker course in her sophomore year. She was thrilled when we met and told me all about her plans and the classes that she had signed up for at William Rainey Harper College for the fall semester.

Juan had always been a hard-working student, and appreciated the opportunity that he had to graduate from a high school in the United States. Juan was happy because he was doing something that his parents were not able to do. Juan had come to the U.S. when he was six years old and had been in the English as a Second Language (ESL) classes before being able to take a Heritage Speaker class with me. Juan told me that he was able to afford to take classes at William Rainey Harper College that upcoming fall. 
Raul was a hardworking and determined young man. He had moved the spring semester of his senior year and had to complete his final semester at another school within the district. I told him that he could have commuted because it was his senior year. He was a good student and would be attending Aurora university.

Anna was a student from another school within the district, and thanks to her former administrator, she was able to meet with me to conduct the interview. She had already started taking summer school classes at DePaul University in Chicago and was the second person in her family to attend a university.

Juanita was another student from another school within the district, and she told me about how she knew another person who was participating in my study. She was the first in her family to attend college and was going to attend the University of Illinois at Chicago in the fall to become a teacher.

Ernesto was a student from the same school as Anna and had a lot to say about his administrator and how she helped him when it came with questions about college. I found out that he was not born in the U.S., and because his parents were working two jobs each to get by, an expensive college was out of the question. Ernesto was able to register for the fall semester at William Rainey Harper College and was able to take a couple of classes and work to pay for the spring semester.

Juanes was a student whom I met three years ago while teaching summer school and had received the invitation to participate in the student study from a former student that now is a school counselor in one of the other schools in the district. Juanes said that he was going to attend UIC in the fall because his counselor had recommended it to him. 
Teresa was a student from the same school as Raul, and she had not initially responded to the request for an interview until she had talked to Raul. She made him feel welcome at his new school and got to know him very well. Teresa and Raul were both in what is considered the best school in the district, and both had interesting stories about their time as students. Teresa was also attending DePaul University in the fall and mentioned that the Latin@ support program at their school had helped her find scholarships to pay for the cost of De Paul.

Irma was recommended to me by the same administrator that suggested Juanes and attended the same school that Juanes attended. Irma was shy and stated that she was not sure how she was going to go to college but that she would figure it out in the fall. I never received an update on what school Irma decided to attend because her parents were in the process of moving.

Carlos was the second member of his family that I had as a student. I had his older sister for three years while she was in the Spanish program. He was active in sports and activities, and because of his involvement, he was on his way to college to get an education but would also be playing soccer. Carlos told me that he was all ready to attend Aurora College in the fall and that his soccer team was starting the fall practices in September so he had to get back in shape.

Amanda was a student who wanted to become a teacher, and in the previous years, she had been a student intern. Amanda was an only child and only had her father at home to raise her. She enjoyed working with the young preschool classes that were offered at the school. She was an active member of the school's student council and worked with the sports team as their manager for the football and wrestling. Amanda said that William Rainey Harper College made the most sense to her because she was able to work there because of the work study program. 
Elena was a student who had transferred in from Chicago during her sophomore year and had taken Spanish during her three years at her new school. She was able to progress to AP Spanish because she said that she had a natural curiosity about where her family had come from. She had told me a couple of times that she was interested in attending Illinois State University because it was far enough from her parents. She was excited but nervous to be leaving her family to go down to Bloomington/Normal.

Andres was from the same school as Juanita and Carlos and was part of the Project Achieve program since he was a freshman. Andres was the middle child in his family and had one older brother who had dropped out of high school to help his family with money. Andres wanted to make sure that he went to school because he saw that his older brother was working extremely hard to support his family, but he was not making much extra money for himself. Andres decided to attend Roosevelt University in the fall and was excited.

Alberto was a student whom I had met during Harper College's Latino Summit and had been one of the students that one of the other counselors had on their roster of students with whom they had met. Alberto was the first in his family to have a chance to go to college, and he did everything that he could to make sure he had all the information that he needed to attend college. Alberto qualified for Harper's promise and was able to attend Harper college in the fall.

Juana was a student whom I had never met before the interview. She had never taken any Spanish classes during her four-year high school career. Juana was classified as being Latina, but she could not speak Spanish very well, and that was the reason why she had never taken any Spanish classes. Juana was going to be attending the University of Illinois in the fall because so many friends were also attending in the fall 
Susana was a former student who was in my Spanish for Heritage Speakers class as a freshman. After her freshman year, she continued to take Spanish but not in the Heritage Speaker track, as she did not want to put in the work. She had a great relationship with the counselor who sent her the interview inquiry. Susana said that she wanted to go to Northern Illinois University because it was close enough for her to come visit her parents.

\section{Research Questions and Themes}

\section{The Definition of Success According to the Participants}

Success is an essential component in the lives of individuals, no matter their age or gender. In an earlier chapter, I offered the definition of academic success, which included factors such as faculty reports, advisor reports, membership in honors programs, grades, academic records, public recognition for academic achievement, timely graduation, independent scholarship, social confidence, interpersonal relationships, and increased awareness of moral issues and social problems (Anastasi, Meade, \& Schneiders, 1960; Richards, Hollands \& Lutz, 1967; Willingham, 1985). Success in life is something that everyone strives to achieve, and knowing that everyone understands success differently is vital to understand the individual and what motivates and drives that person. However, understanding what success means to each person is tricky, and attempting to understand what is essential to members of a similar group can be even more difficult because unless you ask the same focused questions, you may get different answers based on the individual's understanding of the question. For this reason, the ten focused questions allowed me to get specific responses related to the success of the participants who experienced education differently. For this study, the student's own understanding of success and their definitions were used to report their beliefs and understanding of success. 
Success at anything in life is something that differs from one person to the next and is influenced by various factors. Depending on the persons and what they are working towards, success can change depending on what personal goal they have set for themselves. Success can be viewed in many ways, and I believe that what others may look at unsuccessful may, in fact, be considered a success to the person completing that task. Success does not mean that every individual completes that task precisely the same way but that each individual is able to complete it and learn from it. We may live in the same city, county, state, and nation; however, who we are as individuals is what separates us and what allows individuals to reach their own definition of success. However, there have been instances where this is not always the case, when it comes to being stereotyped just because of where I was born and dealing with the stereotype. Being Mexican is what I identify with, and after conducting interviews with various recent graduates from the Northwest Suburban High School district, I have found that schools have not changed to benefit the changing student demographics. The experiences that were shared by the participants depict a system that still believes that even with the documented number of minority students they now serve, everything should remain the same. I find myself having more questions than answers because I know that the district where I have been employed for the past twenty years has the resources to provide academic resources and support to all of its students. Latin@ high school students may need additional help making connections between their two languages, Spanish and English, as well as to their cultural heritage. Adding programs and culturally relevant curriculum will help them will allow them to make the connections needed to achieve academically.

In conducting this research, I explored what success meant to former students who had completed their high school careers. Academically, all participants were successful because they 
met the district's requirements to obtain a high school diploma and are now high school graduates. I found that academic success for the participants was not primarily about getting the best grades possible, but rather about being happy in the end with the choices that allowed them to graduate. After reading the various answers to the questions of what success was to each participant, academic progress did not only align with the academic definition used by scholars. For example, Juana said, "Success for me is being able to accomplish my personal goals and being happy with what happened after the choices I made." She, like others, did not mention traditional academic success in her definition, nor did others connect it to their success in the form of grades or grade point average during high school. Mario said, "Success is my own words, would be something more like a goal that I would put on myself." Their identification with success was on a personal level that had them at the center of the definition. Academic achievement was not connected by any of the participants to grades, courses, or awards received during their high school career. Carlos said, "To me being successful is to take steps toward achieving my goals continuously." Ernesto said, "For myself, that's a hard question for me. Like I feel like success is like the school wants you to succeed, grades-wise, but in life, we're not given grades. We're given money and like um, how, how you accelerate your job position. So like success for me would be like right now me being in a position where I get paid higher and like I see more by like people that are equals in my field, I would say. So that would be a success for me." Amanda stated, "Success for me had the right mentors in my life that believe in me and push me to reach farther than I thought I was capable of. Success is learning to believe in yourself in an environment that some may not see that inner greatness in you. Success is pushing and applying yourself even when you don't want to." Success was connected to their experiences during their completion of high school and was not directly related to their academic 
achievement. The way participants defined success was not what most educators think of when it comes to academic success, in that the majority of participants connected success with general personal goals that they were able to reach. Success was being able to accomplish something that they viewed as vital to them, and their own situation as all participants came from different situations. I found myself reflecting on how I see success as well after reading what participants had to say, and I found myself going back to what Juana stated as her answer to the question of success. Juana claimed, "Success "to her "was accomplishing every goal in life and be happy with the results."

\section{Reflection}

Being able to look at the bigger picture in terms of being happy demonstrated an exceptional understanding of the individual's abilities to relate to the world in which they live. Participants did not connect their definition of success to education or their grades and focused more on the achievement of personal goals that they set for themselves. A large portion of the participants believed that by completing high school, they had attained success and that they now had choices for their future. Being happy with their decisions was a recurring theme, and every one of the participants stated that they were pleased with their choices. I believe that having the option of being able to take college-level courses that would help them earn a college degree gave each individual a sense of fulfillment and achievement. I know that this is one reason why I have always believed that I can do anything and that no one will keep me from my goals of helping more Latin@ students as an administrator and eventually a school principal.

\section{Personal Academic Success}

When asked to focus directly on their academic success in high school, the participants' responses changed because they knew that their answers were now related to their grades during 
their high school career. The majority of the students believed they were successful during their high school career because they all received a high school diploma. Some of the participants stated that they could have done better when it came to their grades, but as long as they were able to graduate, in their eyes, the grades received did not matter as much. Teresa stated, "Uh, yes, because I had good grades, I had a good GPA, I had a great experience during high school. I did a lot of stuff with my friends and various activities that I enjoyed. I hung out with many of my teachers, and I got along with many people." Their understanding of grades and their importance was not the same as what traditional academic success represents. The level of academic success was different among the participants, but their self-understanding, when asked if they were successful, was more critical when they were asked about their final course grades. Participants believed that earning credit for the courses they completed was more important than the actual posted letter grade. As Mario put it, "I do not think they give diplomas if you are not successful." He provided a simple answer to a question that could be looked at differently by different people. Their ability to graduate was a stepping stone for them to have higher earning potential than their parents and will help them in the future. Juan stated, "I graduated, and I'm here, and I graduated, you know, I have a lot of recognition on my belt. So yes, I would say that I was successful in high school." Participants viewed their achievement as a success because they had the opportunity to continue their education beyond high school if they wanted to. Their diploma was something that they could hold, that allowed them to continue their education, which would help them reach something that others in their families had not reached. Raul stated, "Uh, yes, I believe I was successful because I came into freshman year not really knowing what I wanted to do, not really just kind of going with the flow and honestly Project Achieve, which is a group here for minorities, they really helped me out and if it wasn't for that then I 
know I wouldn't have had the opportunities that led me to where I am right now." A real sense of personal accomplishment was echoed in Raul's response. The resilience that these four students showed brings a smile to my face because I thought about my own accomplishment similarly.

Just as I had to go home after school and help with my younger siblings, some of the participants also overcame this challenge and had similar achievements. Juanita answered the question by stating, "Yes and no. Yes, because I managed to graduate with 3.6 GPA, pass my classes all the time. No, because I feel like I could have done more, like taking part in school activities and being more active in changing the environments that my peers were part of, but I was not because I had to help my family, taking care of my younger sister. So it was kind of difficult to be juggling school and then going home and taking care of my little sister who's 15 years younger than I am." Having to take care of younger siblings affected Juanita's ability to participate in activities, school events, and sports, which decreased her sense of belonging. Alberto stated, "towards the last few years? Yeah, because in the beginning, it was just like, oh, I need to make sure I do this. I need to make sure I do that. But it wasn't really for me the last two years I started to figure out who I was as a person who my real friends were, and then it was just a matter of like what I wanted to be in life, where do I see myself? And then I had a certain group of people and teachers that, like, they helped me and like I started to experiment with different things and then I was like, okay, this is what I want to be in life in the last two years of high school. Really made it look like I did have success in.”

Being able to participate in school activities created a sense of belonging and helped Carlos stay on track his last two years. Having a sense of belonging allows students to seek out help from school staff members who are there to nurture those students' interests by their 
participation in clubs, activities, and sports. Amanda stated, "I think in terms of working toward my goals, I was extremely successful. My goals were to be heavily involved in extracurricular activities and to have good grades. I ended up being part of 12 activities, including four honors societies and two sports. I ended high school with an unweighted 3.6 (weighted 4.2) in all honors and AP classes."

Each of the participants shared similar experiences, perhaps because each school belongs to the same school district and because they share the same curriculum and school calendars. While many student responses may have seemed different at first glance, they were similar in many aspects. Each student's stated end goal was almost identical because each student graduated. With their high school diploma, they had the choice to continue their education at a junior college or four-year university. Participants did not use academic information to measure their school success (i.e., their grades); therefore, their responses described what they thought about their academic success. Just about all the participants stated that they were successful because they took classes that they would never have thought they could take and earned a passing grade. Susana, for example, was able to take Advanced Placement (AP) classes that she never thought she would have been able to take and do well in the class. Susana, who was identified by her counselor after taking her 8th-grade placement tests, according to the data, possessed the intellect to allow her to enroll in an AP class eventually during her four years in high school. Eventually, she participated in Project Achieve. Other students said the same, stating that they were pushed to take AP classes that they would never have taken, which was great because they later found out that it saved them money in the form of college credit. For those participants who took AP classes, they were expected to do the work, and the teachers surmised that they had the required prerequisites to be in the class. The students saw, first hand, 
that they had to put in the work because the AP classes were more challenging than any of their other courses. This was different from the other courses they took because they stated that personally, the participants could have tried harder in some of the classes, but in the end, they were happy with their final grades. Mario said, "For me passing was good enough, but I now realize that certain grades that I received had an impact on my future goals and my college choices." For example, some of the participants were taking remedial courses in college because of the grades they received in high school. They were not meeting the requirements, according to their transcripts and had to fill the academic gaps they had in math and English. Now that they were taking college courses, they know that academic success is not just about passing but also about getting the best grades possible, mainly because there are requirements and minimum grade point averages for various majors. Previously, they did not value their grades because they did not believe the letter grades earned were an accurate measure of their success during high school. However, now that they are in college, they realize grades were of utmost importance. As a researcher, I find myself thinking back to my high school days, and I can relate to these students and how they looked at education. Even though I tried my best, in the end, I was often just happy to pass the class, whether it was with a C or an A. I just wanted to graduate, and college was not something that I was working on attending. I never thought I would become a college student, nor did I think that I would someday write a doctoral thesis for that matter. Having a trusted adult who helped me see in myself what I could achieve beyond high school was something that helped me continue my education. Growing up, I had many of the same responsibilities as the individuals I interviewed; however, the job that I had allowed me to buy myself clothes and clothes for my brothers and sister. I never was expected to use that money to help the family. Taking care of myself, meant one less person to worry about. Several 
participants were not so lucky and had to work to support the family, pay for food, rent, gas, and help to take care of their younger siblings. Those that I interviewed were doing their best, and they were happy to be able to pass their classes in much the same way I was. While the letter grade they received was a reflection of their effort in class, it did not reflect whether they were ultimately successful, especially since they are now taking college-level courses. They now have some of the same options as other students who put more value on their grades during high school because of their understanding and goals set by their parents.

Throughout high school, many of the participants did not have the information to help them make better choices when it came to their future. Getting better grades would have had a positive effect on their current academic endeavors, possibly allowing them to earn academic scholarships or get into better schools. A few of the participants did recognize the importance of good grades in high school. Carlos stated, "I think in terms of working toward my goals, I was extremely successful. My goals were to be heavily involved in extracurricular activities and to have good grades." Belief in their own success was usually related to goals and occasionally grades. Andres stated, "I believe that I was successful only in terms of grades. I did not consider myself successful, and I still do not. In high school, what really mattered was the grades. Turning things on time, doing it before the deadline, even though work and effort still had to be put in, learning wasn't valued as much as the actual grade. I would often forget the material after an important test to get an A (or at least hope I did), and that's what would get me through. I can honestly say that there are many things that I do not remember from high school, like in our history or biology class. Not any of the teachers' fault, just the institution as a whole." Based on what some of the students stated, they did not see the correlation between higher grades and 
future possibilities at that time. With that said, it was not surprising to find that the students did not connect their academic success to the letter grades they received.

However, students who had an educated relative or family member to help them were often told how important grades were and valued that more deeply. Many of the participants depended on the faculty who they knew to access this information. Those who helped these participants knew that there were differences between high school and college expectations. These trusted adults contributed to participants' just by sharing their own college experience which added to the participants' own cultural and social capital. The cultural wealth model described by Yosso (2019) explains how students of color can take college courses from their

inner strength. They believe they can succeed, and they use the inner strength to help them deal with the demands of college life. As Bourdieu, Pierre (1984) have shown, inherited cultural capital and acquired cultural capital are essential to the success of individual students.

\section{Reflection}

After reading the comments made by participants, I found that Juan like others understood how important academic success for himself and his peers was to their accomplishment. Academic success for these students was something that they understood on their own terms. This is much the same as I have made all my education my own and have not depended on anyone to do the work that is required to master the material. Even to this day, I still have questions with regards to my education and my content knowledge within the subject area I teach. I attended Illinois State University because of its reputation for its preparation of teachers and my desire to become a teacher. I know that those who supported me had influenced my future goals and desire to give back and help other students like myself. I received a degree with a concentration in Spanish in order to strengthen my mastery of the language, culture, and 
history that make up who I am. Being a native Spanish speaker, I was able to focus on the areas that I still needed to refine before being able to student teach. I know that I was a well-rounded individual for someone who was an immigrant and came to the United States seeking the American dream. The dream was only made possible because of a program, which gave undocumented immigrants in the nineteen-eighties a pathway towards becoming a citizen of the United States. I know that if it were not for that program, I would not be in the place that I am in currently. I know that I have achieved a lot more than what others with a similar history have accomplished. After graduating high school, I believed that I had accomplished a lot as I had something none of my family members had. Today I am well past the expectations of what any of my former teachers, counselors, and administrators had for me. In a similar way, participants thought that they had achieved something of their very own by graduating high school and receiving a high school diploma. This gave them the option to continue with their education if they choose to do so when it was best for them.

\section{Student Support Systems}

Every one of the participants stated that they had support from various people within the high school they attended. Each of the five high schools within the Northwest Suburban District offered different programs to students and one that kept being mentioned was Project Achieve. However, the program that impacted Latin@ students the most was not available to all, according to what participants stated. Project Achieve was identified by participants and was viewed as beneficial by all those who participated in the program. Participants did not meet regularly with their counselors but Project Achieve students, who had teachers that coordinated the program, always met with them for guidance. Participants identified teachers as individuals who took the time to help them when they had questions or needed someone to talk to and with 
whom they could have conversations. Participants were able to create a connection with a trusted adult who made them feel welcomed and accepted. Teachers believed in them, and that was important to them because they were the ones to encourage them. Mario stated, "the teachers were very vocal, and if they noticed that you needed help, they would not hold back and not ask you." The support and encouragement provided to them were extremely important to their success. Having a trusted adult who they could go to when they had a question or just needed someone to talk to was something that participants continued to state that helped them during their experience. For those students having a teacher as a trusted adult created a more profound connection, notably when those same teachers facilitated Project Achieve. These teachers would work with the project members and would get to know them better due to the fact that they also had them in class.

Participants who were part of Project Achieve received more benefits than just working with experienced teachers, who had mentored other Project Achieve students, but were also exposed to support not available to non-Project Achieve members. Project Achieve Students who attended the Northwest Suburban High School district were selected to participate in the Lead Higher Initiative, a partnership between the State and Equal Opportunity Schools (EOS) to expand enrollment to students. During my investigation on Project Achieve requirements, I found that those students who participated in the program were chosen based on eighth-grade test scores. Project Achieve identifies incoming freshman and minority students, and aims to support and teach them to become resilient, hard-working, engaged learners in accelerated AP courses. Those students who participated in learning cohorts throughout all four years of their high school career were provided with an opportunity to learn and grow with the same group of students during some of their classes as a support system. Many of the participants also stated 
that Project Achieve exposed them to college planning, preparation, and campus visits. However, this was offered to incoming freshman by invitation only, according to the district's summer school brochure. It is an intensive English and mathematics skills enhancement at a rigorous level, so students will be able to advance to accelerated level coursework as freshmen and take AP courses during their junior and senior years. Being part of this program was a significant contributor to their success because it exposed them to life-changing experiences and opportunities. Those students who participated in Project Achieve were taught to become resilient, hard working, and engaged learners in accelerated Advanced Placement (AP) courses.

Susana told me that she was able to participate in Project Achieve because she was asked and was smart and worked hard at school. This was something that she viewed as extremely beneficial because the teachers, who worked in Project Achieve, encouraged her. The groups of students continued to meet and receive support from staff members and each other during the next four years of school. Students who participated in these learning cohorts throughout all four years of high school were also able to take part in activities that provide students with a way to learn and grow. Grouping these students functioned as a support system that kept them motivated and allowed them to meet the goal of the program. However, the program did not include all of the Latin@ students. Some of the participants stated that they believed these groups helped them and would have helped their friends who were not part of the program. Their involvement in the program exposed them to educational opportunities that showed them that they could succeed. The lack of educational opportunities is a factor that contributes to low academic attainment and achievement among Latin@ youth. Not including all Latin@s in the program does not provide equal support to all students. Susana comes to mind when I tried to explain the overall goal of Project Achieve. She said, "I had friends that were not in the program 
because they did not have the test scores to get into the program." She stated that she was lucky because she was part of the cohort, and teachers were always on her to get the best grades possible. A trusted adult, as well as a support system created by other students that were working toward similar goals allowed Susana to stay on task. Similar to Susana, Juanita noted that for her, "the positive experience that I had during high school, was being part of the Project Achieve honestly feel like it opened up many doors to me that I was able to come out of my shell a little bit. Someone else said they were behind me, I knew that it was not only my parents that were behind me, but he was behind me, and they were, had the same mentality as I did, trying to push each other to make sure we get to where we want to be."

Teachers were there for these students in much the same way they are for all other students, who also had their parents involved in their educational process. Lee and Bowen (2006) write, "in relation to the parental involvement mesosystem, cultural capital is the advantage gained by the middle-class, educated European American parents from knowing, preferring, and experiencing a lifestyle congruent with the culture that is dominant in most American schools" (p. 198). Participants stated that they had parents that depended on them to translate the school's information that was sent to them at home. Like Susana, many of the participants expressed how lucky they were to have been part of the program. I found that those students who participated in the program expressed detailed responses to the questions, and they were able to express not only how beneficial their support was personally but also how their trusted adult helped them reach their current academic level. Project Achieve exposed participants to college visits, study skills, and course work that prepared them to eventually enroll in AP classes.

Eight of the seventeen participants stated that things as simple as being taught how to take notes and take a college visit were essential and helped make up their mind about attending 
a junior college or four-year university. Moreover, to have someone they could trust to talk to made an enormous difference for them. All of the participants stated that their experience was a positive one because of the teachers and support, both of which helped them when they questioned themselves. Andrea said, "College visits and experience of going to an actual college and taking a tour helped me focus on my future and how education would shape it." Juana, another participant in Project Achieve, stated, "Teachers took extra time to explain and make sure we knew the information and why it was important." They were always encouraged and felt like they could accomplish their goals. Elena stated, "I had a few great teachers that believed in me. One in Spanish class, one in math class, and another in English. Those three teachers saw a spark in me and motivated me. In particular, it was my Spanish teacher. He was always there to encourage me. He even helped me submit my FAFSA when no one at home knew how to submit the application being in a Spanish speaking home. Those kinds of teachers are the ones that made the most significant impact on my high school career."

Elena stated, "I was on the soccer team, and my freshman year, my coach was selecting the captain for the game, he decided captains on rotation, so everyone got a chance. He asked who hadn't been a captain yet. I said I hadn't, and he said I would never be a good leader, so he passed me on and selected someone else. As a freshman, that was one of the hardest things I could have ever heard, and it affected me. I still remember his words from time to time. He put me down, a kid that already had low self-esteem. On a not so personal view, my views on the education system in my high school there was a clear division between demographics either it being social classes like popular, athletes, nerds, fine arts, or races you could see it especially in the lunchroom there was hardly any intermingling." This comment is impactful because it showed that there are teachers that treated students differently based on their nationality. Elena 
being a Latina in her view would not be a good leader and was not given the opportunity as others were. The majority of the soccer teams was made up of white students but a negative view on the part of the coach had an impact on Elena. In a similar way Teresa stated, "some negative views from the school that I went to was that there was a majority of white Americans. And it was, it was basically like shell shock, because the majority of students were white Americans as opposed to the school that I transferred from. Which was more ethnically balanced, um which was positive when compared to the school that I graduated from. The new school was more competitive, which is great because then it makes you like more, uh, more uh, makes you, uh, try to make, do your best and whatnot." Teresa and Elena both shared similar experiences that affected them both. If they did not have a healthy support system in place they could have given up after these experiences.

\section{Reflection}

Participants stated that some of their friends from high school have now said to them that they wished they had been part of Project Achieve. This made the participants happy because they are now in college and having success academically, but it made them sad to know that their friends could be experiencing the same. Aside from Project Achieve, there was no other mention of other actual academic support programs targeting Latin@s in any of the schools. I would have thought that Latin@ students would have had other identifiable programs geared toward helping them academically. When I used to sponsor the Latin@s Unidos support group, I used a program created by the Learning for Life Corporation and focused on developing attainable goals, introductions to career speakers, and college exploration. I also conducted parent classes on technology, scholarship seminars, and used to translate the principal's newsletter from English to Spanish. 


\section{Interactions with Teachers and School Staff}

Teachers made up a large portion of those who encouraged the former students who participated in the study, and they were a resource for students when they had a problem. Teachers were supportive: they took a genuine interest in the students and wanted them to succeed. Moreover, they helped the students believe in themselves. All of the participants also described having a positive relationship with specific school personnel and not just teachers. While I asked participants to discuss teachers, some of them explained great relationships with hall monitors, teacher assistants, and some administrators. The roles they described were always supportive of the students and their education. Mario stated, "My relationship with my teachers were very close. I guess they helped me by guiding me into what courses to take for the next year or even by just saying out loud, oh well, I see that you are struggling with... You should look into studying this a different way and kind of opened my world and my study world to at least two new study methods." The simplest of things seemed to have been the most important to the participants because they knew something that helped them. The advice could have come from a teacher or from any other staff member within that school, but they were all equally important to the students. Speaking of her trusted adult, Elena stated, "Trust was built over years of being able to talk to them and the interest level the adult showed in them." These adults were not questioning them about their grades or their homework. They did not care about students

taking their breakfast out of the cafeteria. The simple things mattered to students, and because of the large number of students who identified themselves as being of lower socioeconomic status; warm breakfast was what they needed in the morning. Anna provided an excellent explanation about why her trusted adult was not a teacher, but one of the school's hall monitors: "I never had to explain myself to her, and she was not on me about my grades or missing assignments. She 
asked me how I was doing and provided just a caring person asking about me and not grades or classes." The relationships were not always about school and helped students who were having a hard time at home deal with that specific day. I know that there are students who have other things going on in their life that have nothing to do with education. As teachers, we build relationships with students just by chance many times. In recent years, I have had the privilege of getting to know some students that have different needs than other students. Helping him get his work done during class helped him eventually graduate and have a chance to go to school. Last year, I had a student who was a sophomore, and at such a young age was already a father. He worked two jobs and was always tired, and sometimes fell asleep in class. I, being the concerned teacher that I am, asked him if he was okay. He told me why he had to work and that he did not mean to be disrespectful and fall asleep in class, but he was so tired. I gave him extra time to get his work in on time, which helped him, and now he talks to me and asks me for advice and has continued to work and go to school.

Amanda, who identified a support staff member as her trusted adult, had a positive outlook on their interactions. She said, "I would go to Cindy every single day, and she would see me and smile, which made me feel good about being there and seeing her." For Amanda, just having someone whom she would go to and get a warm welcome made her come to school. Raul said that for him, "the teachers here were awesome. Every teacher I've met, uh, yourself, Mr. Armstead, Mrs. James, Mrs. Fuentes, my coaches, my history teachers, Mr. Andrews, Mr. Davis. They were all awesome. They all took time out of their day. It was more than just teaching me. They would talk to me about anything that's going on. Tell me about their high school, their cars, experiences, how they went about everything, what went through their heads, how they change their majors, many times, things such as that. So that helped me realize that 
teachers are more than just someone there just to lecture you. It also helped me realize that there's a real-world after this and that I can handle it because there's a bunch of adults here that helped me out." These individuals interacted with the students on an everyday basis, and they were there for them as guides and as trusted adults. According to just about all of the participants, these trusted adults kept them focused on their own goals and on how they could reach them. The trusted adults were not judging them; instead, they would listen to them and give advice when needed. This was a welcomed change for many participants who required someone who would listen to them. Carlos, who made a secure connection with a teacher, said something striking: "Even if I have parents at home seeing this particular teacher helped me feel accepted and important because they genuinely asked how I was doing." Carlos felt that this teacher took a genuine interest in him, not just asking to ask but out of sincere concern. Even when it came time for midterms, or when it was getting close to grades coming out, the teachers who made a connection with these students also asked about the student and not only about school-specific expectations.

Similarly, I still remember individual teachers from my high school experience and understand why these kinds of teachers are so important for students to have. My guidance counselor took particular interest in me, helped me, and made me feel accepted. Because of that counselor, I did not feel different or weird for asking questions that may have seemed like common sense to others.

\section{Reflection}

No matter the difference in age or era, making a connection with teachers and school staff members is essential. Students want to feel accepted. They want to feel like they are a part of a community, in this case, the school community. School is about more than taking different 
classes and taking quizzes, tests, and assessments. Interactions with teachers and staff made a difference in the lives of the students. I believe that this is particularly important for Latin@ students because they are getting valuable information that will help them continue in education. Participants did not seek out any particular faculty member to develop a supportive connection. They were looking for someone with whom they could talk to, relate with, and help them feel welcomed. These simple interactions may not seem like something important, but having someone who is not always on them about their grades and just took an interest in them made a difference to them. The teachers who I know within the district give so much to their students, and I know that the ones who I have helped bring me a sense of accomplishment that no test scores can validate. These students appreciated the time and sense of belonging that made them feel welcomed and appreciated. Each school had some form of support for struggling students, and the focus was always to get the students back on track so that they would pass each of their classes.

\section{Getting Help from the Experts and Planning for the Future}

Many of the participants did not meet with the counselors as much as I would have thought but still had a solid Grade Point Average (GPA). Many of the participants stated that they only met with their counselors when they needed to register for the upcoming year's classes. However, some met with the counselors regularly because they would seek them out. Beyond course registration or changing their schedules, most participants said that they did not visit their counselors regularly. Anna was the exception because she stated, "I would say that in the four years, I met with my counselor more than twenty times. A majority of the times was usually about what the next step, what's the next classes I can take, or maybe how I needed to push myself a little more so I could improve my grades." 
Among those who did not meet as often with their counselors, other adults filled the counselor role, becoming people students talked to about school and what their future goals were. Those who did not meet as often with the counselors primarily depended on teachers, hall monitors, and teachers' aides for their academic guidance. They were able to build a level of trust that allowed them to seek out advice and ask questions that helped them with future educational planning. For many of the students, their counselors did not make an impact on their future. Amanda stated, "To be honest, I do not remember my high school counselor at all. They did not make much of an impact on my life." Those participants who met with their counselors more than the others expressed having a great relationship with them. For instance, Juan said, "Meeting with my counselor for more than to pick out classes was important to develop trust in him. He had time to get to know me and ask if everything was going well at home and in school." Juan's counselor knew his family and talked to his mother whenever she had any questions. Whenever there was something that Juan's mother did not understand, she was able to call his counselor and get answers to her questions. Juan's mother felt comfortable talking to her son's counselor because they both spoke Spanish. The ability to talk to a school staff member in Spanish was important for Juan's mother because she had someone who could answer her questions that Juan may not have been able to explain himself.

Furthermore, those participants who met regularly with their counselors received information that was beneficial to their future educational goals. Like Juan, I also started meeting with my counselor more frequently during my senior year of high school, and doing so helped me prepare for college. Andrea stated, "for me, meeting with my pastor.... He was Hispanic, just seeing that he was able to do it gave me hope that I was going to be able to do it. I didn't even know how to tell my parents that I wanted to go to college and I remember one time I mentioned 
about going to Indiana State because I received a scholarship. My parents freaked out because I was going to be out of state. He kind of helped me talk to them and explain how it's normal for me to leave the nest and stuff. But again, it also helped me that he was Hispanic because he understands like the cultural ties are behind that. I knew that if someone did not speak for us I had to speak for myself and my family."

Other participants offered similar responses to this question about their counselors. Each participant felt better prepared because they were able to get all their college questions answered, which allowed them to begin a timely college search. What I think is important is that few of them considered their counselors their trusted adult. The caseload that most counselors have on top of all their other requirements, makes it difficult for them to meet with students more than a couple of times a year. Students stated that if you did not seek out your counselor on your own, you would not seem them but for the minimum number of times, and it always focused on picking courses. Andres stated, "I would meet with my counselor when she told me to meet with her for classes and information about the ACT and SAT when I was a Junior. I would get good information whenever I remembered to ask the questions I had, but I never really did meet with my counselor." Raul stated, "I probably met with my counselor like every, every semester just for classes. Other than that, I never really met with her. That was until she told me about Latino project my freshman year where you like to go to Harvard, and that was about like the only special one that I remember that really helps, like, with my education, but other than that, everything was online. It was pretty self-explanatory, and you would just talk to your regular teachers, like talking to people, and they would kind of tell you what to do. And so I really don't feel like the counselor or did that much. I don't feel like they guided you as much in education or like helping you decide what school to go to. They were just more like, what do you like? Like 
you need to go visit. They didn't really like to emphasize the differences between this school and like the type of people." Teresa stated, “Oh, I did not meet with him or her a lot because I will always ask my teacher for help because I didn't really need my counselor. I would go see my favorite teacher and ask him what I needed to do. My teacher gave me the information that I needed, the things that I need to do, so I didn't need my counselor.”

\section{Reflection}

Having a trusted adult in whom students could confide, allowed them to feel comfortable and ask questions with confidence. Knowing that their trusted adult would help them, regardless of the questions they were asking, was extremely important. As a teacher and someone who has gone to college and figured it out on my own, I know a lot about college and what my own children must do to get ready for it. However, I do not have access to the software, sites, and other resources that can better assist students when it comes to some college preparation. Scholarship opportunities, transcript requests, and application deadlines were known by my friends, who had someone in their family who had gone to college. However, I did not know any of this, not because I didn't care, but because I did not understand the process. As a teacher I often get asked for recommendation letters in the fall because different schools have different due dates, however, this is done by students who are doing well in school and know they need recommendations. I have never been asked for a recommendation letter by students just to have one because they have not planned on anything further beyond high school.

\section{Keeping Up with Important Information}

All participants stated that their schools provided them with current information about their academic progress. If they were not performing well, the teachers in charge of that group of students contacted them about missing assignments and missing work. The staff wanted to find 
out what the students needed to get them back on track so that they would not wait until the last minute to complete schoolwork. Midterm comments, parent phone calls, and in-school interventions were at the core of keeping students informed. Participants stated that their teachers, who also served as their coaches, activity sponsors, and study lab teachers would keep up on their grades and provide them with information when they were concerned with something that was happening. For example Mario recalled being told, "I see that you are dropping in these grades and you should or should not be doing this or that" to help him get his grades up. This occurred when Mario was in a guided study room where teachers were required to keep track of the students, who had missing or late assignments in their infinite campus portal. Andrea stated, "I mean I don't know as far as the rest of the school goes because we were able to check our own grades online. As a member of Project Achieve we had to have meetings with our counselors and the teachers that participated in the project in order to make sure our grades were good. We had to make sure we kept track of our grades and if we were falling behind we would get help to get us back on track. The teachers had to set the idea that success is really just doing your best because they did warn us, you guys are gonna struggle and like that's perfectly okay. Teresa said, "Being in a guided study hall where we had to check our grades and fill out, our progress report helped me stay on task and or get back on track." In recent years, I have worked in these guided study halls where we try to help students who are falling behind or are not doing well in their classes. Every time we see the students assigned to our guided study class, we print out missing assignments to help them focus on missing work, so they don't fall further behind. Raul said, "They're pretty good at telling us different strategies. There were before and after school programs that we could take advantage of. They had like extra classes you could take if you needed more help with math or reading. However, I don't think they did an outstanding job of 
showing us our academic progress. We could see our grades but trying to figure out our individual GPA was difficult." The more information that we are able to provide to students, the more they can stay on task and not fall behind. If students fall behind, it will be harder for them to stay motivated and may cause them to give up because of other issues that may be affecting them. Irma said, “They provided a pretty good amount of information. It wasn't about them like giving information yet it was more like they would inform you like we have things here that you have to go out to your time to go see them because they're not going to like, they can only do so much to help you with your future and wants you to do something about it. It's more like you'd have to have the self-motivation to go to them, and then they bring in and provide everything that you need, and that's what really is advisors like yourself and trying to motivate yourself to go out there and find that information. They'll tell you that we have it, but it's more like we're not going to tell you until you actually sit down and want to come to us." The students' experiences with their counselors may point to a need to change the way that at risk students are treated. The number of students classified as at-risk continues to grow, and yet the procedures are the same for all students, when it comes to meeting with their counselors. I know that my counselor, for some reason, looked at my grades and started to ask questions that I would never have asked while presenting me with alternatives to my original goal of working a job that did not have many options. The numbers presented regarding the school district show that this is something that must be addressed because of the changing demographics of each school. Anna said, "Rarely would my counselor give me individual information in regards to my in progress grades as I would only see my counselor to register for classes. Occasionally, your teachers would say, hey, check infinite campus to see how you are doing. The campus grades are up, or there might be missing assignments, but other than that, they would not say to you, hey, let me talk to you 
individually. It was more like if the student had a problem, it would be their responsibility to talk to the teacher or go seek help."

\section{Reflection}

Participants were also contacted when they were doing well and would be congratulated and rewarded with additional free time to do school work outside of the study labs, which had been created to help all students. Students who were struggling were easy to identify, and their schedules would change and they were moved to a study room, where they would get individualized attention from the teachers who were in that room. As Anna stated, at times one needed more than just a little help, "You need pretty much like a 'whole team' that can help you with what you are struggling with." There were participants who stated they did not feel 100 percent supported, and that was a direct connection to them not being sought after by their teachers, counselors, and school staff. If they did not seek help, they would have been looked at as doing fine and would not have been called on unless they were failing.

\section{Cultural Perspective from School to School}

Participants provided varied responses to the questions regarding the cultural perspective that they had formed, in part, because they did not all come from the same school. Each school viewed the cultural of is students body differently and this could be seen in the clubs, celebrations, and announcements celebrating the diversity that existed in that school. All participants shared one thing that distinguished them from other students, in that they all identified as themselves as Latin@s. Each school's recognition and acceptance of cultural diversity depended on the percentage of Latin@ students in the school. Each of the five Northwest Suburban High Schools varied in its rate of non-white students. The explanations provided by participants parallel the degree of cultural diversity and awareness found within 
their school. For example, schools with a large minority population promoted a school culture that was accepting and nurturing for the most part. Participants from these schools stated that their culture was present in activities, dances, and everyday school functions. According to their responses, participants attending these schools felt like they belonged. They felt that everyone was accepting of their differences, welcoming them and celebrating them. Each school had different clubs, groups, and functions, in which all cultures were put on display in front of the rest of the student body, which generated interest among the students. The school where I work had at one time a cultural awareness club, and they performed in the spring for the student body. However, announcements disappeared overtime when it came to celebrating Latin@ Heritage month, African American history month, and other months that celebrate the school's diversity. The clubs helped bring together students of the same cultural backgrounds, which made them feel welcomed and allowed them to be themselves. Irma stated that the Latin@s support group at school was a way for her to meet other Latin@s, listen to music, and plan school activities. Irma also said that if it were not for the Heritage speaker's classes, which were offered to Native Spanish speakers, she would never have taken Spanish in school. These classes are different from other Spanish classes because they focus on the Latin@ culture and its connection to the rest of the world. I loved teaching these courses because I was able to create a timeline that connected to significant events, showing the students the importance of Latin@s, when it came to the world stage.

Many of the participants also had after-school activities that they could participate in to feel even more connected to the school. The school was a place where they could go and where they could forget about what was going on at home, a place where they met supportive staff members in all sorts of capacities. Andres recalled how the school had a support group for 
Latin@s, which gave them a place to talk about anything and to ask any questions among their peers and sponsors, who were supportive of them. Andres stated, "We had an optional school assembly where classes were able to come down and view the dances that we worked on during the club meetings. Being part of the club allowed me to give back to the school because this was the only way to participate in school activities." Such activities were the only form of additional participation available to many students. Many had to work and could not play sports or engage in other activities that required them to be at school for extra time. To echo Anna's comments, when I was in charge of the Latin@ mentoring group, I had to ask when everyone could attend and keep the day and time the same for the entire year. I also knew that I could not require everyone to participate in each meeting because many of the students had other responsibilities at home, from taking care of younger siblings, to working a job to help their families.

Participants who came from schools with a small Latin@ population felt out of place and out of tune with what was going on in school. These students said that you had to do what they told you, and you were expected to know how to do everything that everyone else knew. Those who did participate in sports and extracurricular activities at schools with lower percentages of Latin@ students talked about how money played an important role. Students who did not have the money to buy the name brand items like others had felt out of place, and appearance to them was important. They wanted to fit in with everyone else and wanted to be part of the school as the other students were, but money was an issue. Alberto said, "I went from a school that had a large diversity in its students to a school where you had to look for other Latin@s. There were no clubs or activities aimed at the minority students, and you were expected to be part of the current school culture." Students went along with the culture at that school or what school culture had been established at that school since it started to offer classes. Within the Northwest Suburban 
School District, each school has different percentages of minority students which affect the culture of the school. All the activities, from homecoming to prom, were the same for everyone at each school, however traditions and activities offered to students were different. School culture, for the most part, is similar from school to school and identifies with the majority culture of the school because of the school's history and customs. Each year, for the most part, looked similar and while there may have been some differences between the schools, most followed the same pattern of fall kickoff, homecoming, and dances all being part of the school's history and tradition. Amanda stated, "My high school had some programs for Latino's and it was a safe place for all Latino students it was called Latinos Unidos. I met many of my friends through this

program. It helped us unite based on our upbringing and our Latin cultural norms. Being a part of this organization made me feel like we had a place to call home."

According to many of the participants, schools were not worried about highlighting the diversity of their student body; students were expected to do what the others did. If you were not in trouble in school you would just continue taking classes and eventually you graduate.

\section{Reflection}

Participants at these schools took part in the groups, activities, and clubs that were for all students and not just for Latin@s. They did have the same support in the form of counselors and teachers who took an interest in them, but it just did not seem like the school they had graduated. These participants all were recent graduates from one of the Northwest Suburban High Schools and identified differences when it came to what each school did for their Latin@s. Participants remembered how they felt during elementary, and junior high school, and their time in high school required them to adjust to a new school and the culture of that school. Participants had to adjust to the new school and figure things out on their own. Alberto viewed this as a lack of 
support given to him as a Latin@ student, which made him feel like an outsider. He said, "I was not a contributing member of the school because I did not play sports nor was a member of a club and just was there to get an education." He had responsibilities that other students did not have and had this affected the extent he was able to get involved. Alberto also said, "I had to work since I was a sophomore in high school, and that has helped me save money for college." Alberto, and other students like him, completed school and graduated but did not feel like the school was interested in doing anything else for him, apart from getting him to graduate. Andrea said, "I did not get information on what I could do. I was undocumented and did not know what I needed to do to continue my education. I would have liked to have had information about what I could do as an undocumented student." In this case, the actual college entrance process of deadlines, due dates, and college visits was not thoroughly explained. This could be because of the expectations the schools had and that students should know the information that collegebound students should know.

\section{Different Ways to Help All Students}

The academic and cultural support system available to each of the participants varied from school to school and depended on the number of Latin@'s that made up the school's student body. Depending on the school, culturally responsive support offered to minority students varied and was not the same even when all schools were in the same districts. The support provided to Latin@ students was in the form of clubs, classes for heritage speakers, and volunteer for school cultural presentations. Similarly, the participants' answers to the interview question regarding how they viewed cultural support given to them was different based on the school they attended. Each participant seemed to have experienced different levels of staff support at different schools. For example, in contrast to Alberto's responses in the section above, 
Ernesto said, "The classes for heritage speakers helped fill in the holes that I had about my culture and why they are all connected by the Spanish language." Despite apparent differences, however, all participants stated that the school did try to provide some educational and cultural support in the form of classes and support groups. All participants said that because of the trusted adult they had, they felt good about going to school and taking part in what the school had to offer. All schools with a sizable Latin@ population attempted to show support for their Latin@ student body, and their encouragement helped them complete their high school careers and become successful in their own eyes. Carlos said, "My school was very diverse, and we had cultural presentations where we learned about certain dances that were part of certain cultures." Some participants stated that the schools supported them, but only when it came to school issues and stayed away from cultural representation like providing someone that represents the demographics of the student body. Having someone that Latin@ parents can talk to without needing an interpreter would provide a role model for students and an adult parents can talk to. Juana, for instance, said, "To me, it seemed that the support was offered but was not the same as other schools from what my friends told me." The schools were not concerned with other aspects of the students' lives or the differences that do exist within the Latin@ population, as not all have the same cultural background, and not all are from the same country. According to Raul, who transferred from one high school to another within the same district during the school year said, "Teachers at my old school treated me with respect and wanted to help me. At my new school the teachers were just there to teach us and did not seem to care." Raul also said that teachers at the new school would be there to teach; either you were there to learn or risk falling behind. Before he transferred schools, he said that his experience was a positive one, and he had 
plenty of support. Many adults at his old school were ready to support him, and he missed that at his new school.

\section{Reflection}

Participants' perceptions of culturally relevant support in the form of student support groups, parent groups, and heritage speakers courses within each school were different because of the different percentages of Latin@s in that high school. Participants did not have a common way that culture was presented and celebrated within the high school they attended even if they were part of the same district. The more minority students that went to one of the five Northwest Suburban High Schools the more activities were aimed at supporting these students. At three out of the five high schools I know that they had a Latin@ club similar to the one that I sponsored and focused on college exposure for these students. Each year the same three schools would take their students to the Harper College Latin@ summit, where students would learn about college requirements, financial aid, and services offered to new students. This was something that only some of the schools participated in each school were able to take advantage of because of their participation in the schools Latin@ club. I know that I offered these opportunities to those students who were involved in the Latin@s Unidos support group.

\section{Helping Students Continue their Education}

Each of the participants who took part in my study was successful, despite the challenges they faced. Their families were affected by various issues like parental earning power, language spoken at home, and lack of higher education by their parents. All schools need to continue to make every effort possible and adopt new policies that will promote racial and structural equality within the educational environment. Schools must look outside the district for minority teachers, counselors, and especially administrators, who can know from experience what these students 
and families are trying to overcome. Yosso (2000) wrote that the majority of the students experienced resilience in their current life situation. Students from under represented groups are affected by factors that are out of their control can succeed, as evidenced by the students who took part in this study. For many of these students, their continued participation in the educational systems showed a level of resilience that is encouraging. These students could have given up, but with a guiding hand and a caring, trusted adult, they were able to succeed.

Participants stated that the current programs were more than enough for them and that it provided them with what they needed. Anna stated, "I was provided with information about scholarships, about college fairs and opportunities for minority students that were extremely important. However, since I had friends in other schools, this was not always the case." Ernesto said "I know during summer school that they did have the program for Latinos or like people that weren't born here. Um, so that was a good opportunity that they did provide for Latin@s. But why did the school not open it up to everyone, they open it for certain students. There could've been other students that could also have taken that opportunity, but I don't think like they were provided that information to everyone on how to be part of the program. So I feel like that's what the school was lacking at that time or is lacking at the moment." Being able to see that there were other students that were not able to benefit from this program shows that participants that were part of Project Achieve were thankful for being in the program. Juanes said "Well, um, so in the school that I went to, it had a program in which anybody can take Advanced Placement classes (AP) and so it's, it's usually better for people who don't need the AP class to graduate but are for students that would have a low chance of getting into an AP class. This allowed them to see what it would feel like to be in basically; basically, it will let anybody try to feel what a college-level course would be like." Irma said that for her, "I don't even think they lacked 
anything because they did everything they could do. Like we had several tutoring centers, had teachers that would stay after school just to help a certain student. We had ACT prep and SAT prep, but really it's just a matter of you just got to go out there and look for it." The responses from these participants showed that support was offered but it was not advertised and did not target those that needed the help.

\section{Reflection}

The majority of the participants who were successful participated in various schoolrelated programs aimed at helping students succeed. I know that the ones mentioned were aimed at all students; however, the one that focused on Latin@ students were few. This study identified Project Achieve as a significant contributor to their success. The exposure that they had when it came to academics was what set these students apart from the others who were not in the group. If this program worked for these students, then it should be implemented for all Latin@s, no matter the school, and would increase the opportunities that they would have. Providing opportunities and targeting those that may need it gives them options and allows them to seek out these opportunities when they are in need.

\section{Cultural Support and Acceptance}

After examining the participants' responses in order to identify personal strengths, I then looked for ways that school support influenced their success. The participants' responses helped me recognize that the participants were able to form positive relationships with their trusted adults, teachers, counselors, school staff and administrators. This increased ability to believe in themselves and their ability to adapt to the school's environment. Within the school environment, there were trusted adults who formed caring relationships and had high expectations for the students with whom they were working. Juan stated, "Honestly if it was not 
for the relationships that I had created with my teachers, I felt like the school did not want to give me much." Anna stated, "My parents don't speak English, so I always had to be in every event translating or sometimes, or they won't be able to be at the events. I had various other chores that took time away from my studies. Having to serve as a translator for my mother who wanted to get involved was something I should not have to do. The school talks about getting families together and getting them involved, but sometimes it is tough to get certain families involved. The parents that come said that it's a little bit too early for the parents that actually want to engage because they have to work. My parents always wanted to be involved, especially my mother, but unfortunately, the majority of the time, it's like she had to pick up another shift at work a second job, and she would feel so bad because I go to get all the papers that they give out." Not being able to understand what the parents of these students have to deal with shows that these parents are having to choose between work and school events. Not all events can be changed, especially the athletic events that take so much out of the school week. Irma stated, "Well, for me, as I said before, the school was accepting of everyone's heritage and culture. There were so many different ethnic groups that there was no competition among these groups, it's like everyone's pretty much the same and treated equally. Culture did not matter because they cared about who you are mentally, who has the brains. There was no one really looking down at each other based on their culture. It is just a matter of what you can do in the classroom and what you can do with your academics and future life. It was just a matter of like, okay, do you get it or do you not get it that and then how hard are you going to work." I would think that the diversity of the school would make the school richer when it comes to acceptance and the celebration of its diversity, but as Anna stated it was about your academic success. Gonzalez and Padilla (1997) wrote that a supportive academic environment and a sense of belonging at school 
were significant predictors of resilience. Elena said, "The effect that the academic and cultural support system at my school had on my academic success was that it was a love/hate kind of relationship. I grew accustomed to routine because we were told to take certain classes and certain electives in order to graduate. I was reliant on an institution that taught and told me what to do, what to wear, how to act, and how to behave. As soon as I graduated and that routine was taken away from me, I felt lost because I was not sure what to do after. I knew I wanted to go to college, and I knew what to do because school taught me how to apply, but I myself just did not feel satisfied. I don't really know what my true passion is, and I know many students can relate." High school routines were part of every student's day, and from Elena's response, you can see that there was no real emphasis on culture in the school. Ernesto stated, "Culturally, it's like being a Latin@. Everybody tells you that as a Latin@ go to school, be more than you are currently. What your current parents are. So that does push you. Um, cultural wise. Like in what sense? As you could, you did not hear that from an American teacher, as you heard it from a Hispanic, like go to school, get good grades, focus on that. Like, do not just sit back and be like your father, as your mother, like that, encouraged you. Like if you had family in school, they pushed you. So I feel like academically wise like sometimes school doesn't really help you. Like it's more like your community helped you build you up." Participants were part of the school community and hearing that they could succeed gave them support. As stated in earlier chapters, participants spend a large portion of their time in schools where they would interact with their trusted adults to get the support that helped them graduate and have the opportunity to go on into higher education. 


\section{Reflection}

Within this chapter, the experiences of seventeen former high school students were described using the participants' narrative voices. I wanted to present participants' experiences and insights by using the participants' direct quotes the interview transcripts. Through descriptive narrative, I sought to identify critical factors that supported each participant during their high school experience. Being able to understand the participants' experiences before entering a college or university was important. The participants in this study represented former students from the five high schools found within the Northwest Suburban High School district where I work. Just within the last five years, the percentage of minority students has increased within the district, but the rate of minority teachers has remained at a constant six percent over the five-year period (State Report Card, 2017-2018). During the same period, the rate of minority administrators has remained constant at six percent, which does not match the growing diversity that make up the district as a whole, as well as each individual school. I found that out of the thirty individuals that held the title of administrator only five were minority administrators. I compared the number of administrators listed to the percent of average minority students within the district and found that the $6 \%$ of the identified administrators was well below the average of $51.4 \%$ of students that identified as minority (State Report Card, 2017-2018). The percentage of students represented only those identified as Latin@, African American, and Asian students and did not include students that identified themselves as American Indian or Alaskan or students identifying as being of two or more races. If the teachers and administrators would be representative of their student body, then students may be able to better relate to teachers, administrators, counselors, and support staff. The various experiences narrated by a group of former students that are often identified in literature as 
marginalized, because of factors listed previously, supports the need for more programs aimed at helping these students. Understanding what helped these participants succeed allows those who are interested in assisting them to bring about change. The type of change that will help others repeat what worked for these former students is essential and needed. Literature indicates that socioeconomic status, parents' educational attainment, growing up bilingual, acculturative stress, and lack of exposure to learning opportunities keep students from having success. School districts have the ability to alleviate students' acculturative stress, and provide exposure to learning opportunities. Each of the narratives presented was different; however they provided a picture of the resilience students developed during their high school experience and who and what helped them along the way. The participants' stories presented a deeper understanding of their personal experiences and what other students may need in the future. All participants received support from teachers, staff members, and counselors; however, many only met a minimal amount of times with their counselors who could keep them focused on achieving specific graduation requirements.

The study shared how staff members helped students, whose families had little exposure to the education system obtain a high school diploma. Participants believed that the help they received was critical in their success. The type of support needed depended upon the student. Some students needed more help than others because of personal issues at home, including having to work to help pay bills and other responsibilities. When current students have access to some of the support factors that these former students tapped into, they may also be successful. Participants achieved their personal goal of graduating from high school and having the option to continue their education. 
Participants responses demonstrated that schools still lack a consistent method ensuring that all students have the same opportunities in high school, from academic checkpoints with counselors to ensure they are on track to college admittance. There is no guaranteed way to ensure that all students will reach a level of success that is both personally and academically desired. However, the participants in this study showed that all students do not spend the same amount of time with their counselors, which affected their future education and planning. The former students received support from not only their teachers or counselors, but also hall monitors, support staff, and teacher aids. I learned that students, in many instances, still need someone that believes in them to help them continue their education, in much the same way that I was helped and pushed to go to college 26 years ago. What is surprising to me, and also related to my personal experience, is that students still have to ask for additional support instead of it being something that is offered as a matter of course, to all Latin@ students. If students did not seek out counselors or other staff members on their own, according to participants they would just have followed what others were doing. Participants explained how they had to seek out help on their own and how this help supported them and built resilience in themselves. If participants were just given the minimum number of meetings with their counselors they would not have been able to meet their expectations. This process indicates that schools need to change this practice and implement more academic checkpoints that will support more Latin@ students.

I also found that the level of support varied depending on the high school within the school district, the participants attended. In some schools, there was no real support system for Latin@ students, and they mostly had to go with the flow, as they stated, if they wanted to be part of the school culture. The participants who had access to clubs and or activities aimed to support the Latin@ community felt welcomed and valued. 
In the schools that did not offer a Latin@ founded club, activity, or mentoring group, students felt like they were not part of the school and could not call it their own. While they followed the school culture and participated in it, they did not feel as being part of the school; they were just there and had to keep up. Participants primarily talked to their counselors when they had questions about academics related to graduation and the upcoming school year. Patricio was an ESL student who came to the United States just four short years ago but was able to learn English and take actual college-level classes, while he was at one of the schools. Patricio said, for instance, "If I had not asked about college, I do not think I would not have had the conversation that changed my life my senior year." Assuming that every student has the same information when it comes to education is something that causes some students to go through the motions, without understanding why.

\section{Conclusion}

After conducting this study, I am troubled by the fact that these students did not feel they were part of their school's culture. Perhaps I am troubled because the experiences that I had during high school had such an impact in shaping who I am today. I still remember the school fight song word for word, and I always remember the different official student functions that were part of the school year. These memories are linked to life lessons that came directly from the school's culture that I became part of because the school cared about its Latin@ population. For that reason, schools with large Latin@ populations need to do more, not only focusing on the academic side of the student experience but also focusing on social and extra-curricular activities. Doing so could help so many of the students who were not included in the same activities as those participants of this study. 
Each of the student participants had more than one person, beyond their counselor, whom they looked to for help. Various support staff members offered some form of support to these students. I found that some schools, even those that had a sizable Latin@ population, did not provide many support systems aimed explicitly at helping Latin@ students. Out of the seventeen participants who were interviewed, fourteen were participants in the Project Achieve program. They were considered students who had a chance to take AP courses during their four-year high school experience. I have never worked with Project Achieve, but wonder if it is successful for those whom I interviewed, then why is it not implemented for all Latin@ students, even those who may need more support than the highly motivated students who currently make up the group of Latin@ students? Those participants who were former Project Achieve students stated that the support given to them was significant. It helped them complete their high school careers. For example, Alberto said, "I was fortunate to have been part of Project Achieve because I received the help that others did not and was exposed to other activities that made me want to go to college." These students understood that they were being encouraged to do more in high school and college.

As mentioned in Chapter 2, Latin@ students generally do not have access to the social and cultural capital that is taken for granted by those who are part of the dominant culture or society. To recall Sullivan's (2002) interpretation of Bourdieu, "Cultural capital consists of familiarity with the dominant culture in society, and especially the ability to understand and use 'educated' language" (p. 145). Participants stated they were introduced to new vocabulary that was associated with higher education. In particular, those participants who were Project Achieve students were exposed to this social and cultural capital from teachers and exposure to college 
personnel. Other students would undoubtedly benefit from Project Achieve, and adding more students to the program could produce more college-ready students.

The participants were all grateful for the support and the efforts of their trusted adult. Each participant developed trust with an adult, and often, all district staff members made up the support system. The experiences with district staff members helped shape the participants' views on education, their future goals, and their ability to reach these goals. The participants whom I interviewed were successful. They were all either attending college or taking a college course at the time of the interview. The students expressed what success means to them and how they interpreted it. After interviewing them, I believe they were all successful in their own ways. Each participant shared a similar level of self-reliance, and that self-reliance was paired with the support they needed to accomplish something that many others in their family had not. Because each of the participants received some form of support during their high school experience, they now have the opportunity to chase after a career and a goal. The same desire was sparked in me when I was told by someone I trusted that I could do it because someone I trusted believed in me. Additionally, having someone who knows how to get there was extremely important not only for me but for each of the participants whom I interviewed. While the participants' home lives were also similar to mine, they all had their struggles that they had to overcome.

There were, however, participants who stated that each school could do more for the Latin@ population. They felt that school support should include everyone. Carlos said, "I know that many of my friends who were not in the same situation as I am today, and this is because many more would benefit from such help and support." For Carlos, doing well in school was not the only thing, or even the most important thing, on his mind during his high school career. There were many other issues that he had to overcome that were personal and not easy to fix. 
Elena shared Carlos's view because she also had many high school friends who were not able to continue with their education because of family responsibilities.

From the responses of each participant, I learned that with the right type of support coming from a trusted adult, anyone could reach a dream and become successful in their eyes. College was a dream for many, but thanks to a caring adult, these students are pursuing that dream, which is a way for them to get out of poverty and, more than anything, gain respect. They know that they can now help others who may be in similar situations. The support they received helped them build cultural capital. They are now college students, doing something that many in their family had not been able to do. They are thankful that an adult, who was a stranger at first, took the time and wanted a better life for them. The opportunity to get to know a staff member made them feel part of the school and alleviated the stress that, according to some, caused friends of theirs to give up on education completely. Carlos said, "My friends now see me and ask how school was? I answer them and tell them hard but worth it because they were going to college. They were followed by my question of why they are not going to school." Listening to each participant's response to the questions brought back countless memories and proved yet again that support given to minority Latin@ students is still essential.

The policymakers, researchers, educators, administrators at the school and district level, support staff, and the future represent a large number of stakeholders within the U.S. that have a long-standing interest in the increased success of students. Understanding what helped the students in this study can be used to create additional programs to support the students and parents that may not have relevant information regarding the next step after high school. My research identified vital factors that help seventeen recently graduated students graduate, obtain a high school diploma, and have the opportunity to continue their education. The participants 
whom I interviewed were able to access personal, family, and school resources that helped them deal with adversity during their high school experience. A large portion of the participants did not identify themselves with the traditional definition of academic success because they viewed their recent graduation as giving them a victory. The study also found that while the schools that these participants graduate from made a quality effort to assist all students, the success of these participants should not be used as an indication that racial and structural inequalities were not present during their education. These participants were considered successful despite the challenges they faced that still require more research. The level of resilience they showed even though they had to overcome other factors they had no control over was a key to their success. The schools need to continue to make every effort that will help more of these Latin@ students. The need to adopt policies that can promote racial and structural equality within the educational environment of all Latin@ students no matter the school was identified, representing relevant student accounts of their experiences. The narrative from each participant gave an insight into their experiences and how these experiences influenced each participant during, and now after they graduated high school. 


\section{CHAPTER V: ANALYSIS, RESEARCH FINDINGS, RECOMMENDATIONS, FUTURE}

\section{STUDIES, AND CONCLUSION}

For this study, I interviewed former high school Latin@ students to understand what helped them succeed during their high school careers in a large suburban district. Within this chapter, I will focus on identifying critical connections with the research findings and the related literature on the topic. After reflecting on my research, I have found that the needs of Latin@ students have not changed in the nearly twenty six years since I graduated from high school.

There are a multitude of stakeholders within the United States who have an interest in the study of academic success among the Latin@ population. The literature provided evidence that even when a student receives support from the school they are attending they may still be affected by factors that cannot be ignored, or easily overcome. Socioeconomic status, language, cultural background, and access to outside educational opportunities are factors that cannot be changed easily within the school system. The higher educational system in this country is complicated, and I know that even in the amount of time I have been teaching, it has changed. Students who do not have someone who has completed the process and can share their experiences with them need to seek out those who have this experience. Projections show that the Latin@ population growth at the district, state, and national levels will continue, and adding to the research of success among this group will help others. The literature identified five factors that affect academic success among Latin@ students, including socioeconomic status, parent's educational attainment, growing up bilingual, acculturative stress, and lack of exposure to learning opportunities. The parents of those students who are identified as coming from a lower socioeconomic status may have been impacted by limited academic opportunity and attainment. Statistics have shown that with a higher education degree, individuals have more earning power. 
I believe that education has provided for my family a life that I would never have been able to obtain otherwise. I have been able to provide my children preschool opportunities and access to other programs. These learning experiences are not available to all families. Many Latin@ students grow up bilingual or Spanish speaking families. Those students who speak Spanish at home have to work hard to learn English in school. They are always making connections between new vocabulary learning and the language they may speak at home. If the schools these students attend do not provide quality bilingual education, being classified as bilingual or an English learner can hinder their long term academic success. Bilingualism is an asset but many Latin@ students are not getting the necessary support from schools. The often inadequate bilingual education programs, that continue to be cut within all districts, is a factor in school success.

In addition to cultivating the asset that is bilingualism, through quality bilingual education programs, schools can also address the acculturative stress that many bicultural Latin@s feel in high school. As I mentioned in chapter two, there have been few studies that have examined the role that schools play in the acculturative stress among Latin@ students. Because schools are the gateway to American society for many immigrants and other ethnic minority youth (Olsen, 1997), this topic demands considerable attention. In all cases, immigrants must make many complex choices when they come to the United States, and countless challenges face those who choose to leave their country for the American dream. For many of these students, schools are their one connection to the mainstream American way of life. Providing them with more programs that can help them feel welcomed and supported would go a long way towards assisting them to become part of the school's culture. Smokowski \& Bacallao (2007), "identified biculturalism as a way to cope with acculturative stress. According to this 
view, one preserves his or her ethnic identity and creates a positive and constructive relationship with the new, dominant cultural group" (pg. 279).

Latin@s who come to the United States from their native countries have to try and fit into the dominant culture, as well as the school environment in which they will participate if they are to get ahead. Participants in my study expressed a need to make connections with a trusted adult, whether it was a faculty member or school staff member, who gave them advice. Again, many white students already have these kinds of relationships because of their cultural capital and institutional knowledge. These students had someone who helped them get from high school to college-level classes. At its core, my research sought to understand what motivated the participants not only to continue their education but also to believe in themselves, especially when they did not always know what their next steps would be. I wanted to identify critical factors that helped each participant gain a personal and identifiable level of success, including elements that might be used to help other students with similar backgrounds and needs. The participants may have come from different schools within the same suburban school district, but they all shared similar responses to the questions asked during the interviews. This study yielded additional insights into how participants defined success and who provided support to them while they were in high school. Many times students relied on support staff more than counselors and administrators, knowing that these staff members were not just interested in their grades in a particular class, but in them as people. As described, participants believed that they were successful and now would have the opportunity to continue their education at a community college or four-year university. 


\section{Research Findings}

I have been teaching for 25 years and believe that the educational system has not changed in response to the changing student population. The numbers in my district continue to show an increase in the number of students of color from lower socioeconomic status, but the faculty and especially the administration, does not reflect similar change. The participants whom I interviewed described experiences similar to those that I had to deal with when I was attending the same high school. This more than anything shows that change needs to happen and that the understanding of these students is something that escapes the decision-makers in today's schools. Students who do not have all the necessary items to survive from a well-balanced meal, warm clothes, to a safe place to call their home, need more than what the schools are currently providing. For example, literacy-focused programs that help address the gap between student groups will benefit them and the school as a whole. However, there is more importance placed on standardized tests than anything else, as year after year, teachers are presented with numbers that show that our underrepresented students are not meeting or exceeding on core areas of study. Standardized tests are affected by the community demographics, and the family-level variable strongly influences that test scores, which has already been well-established. Tienken (2017) wrote that median family income is a strong predictor of SAT results. Other factors strongly linked to achievement on state standardized tests include parental education levels, the percentage of lone parents in the school community, and the percentage of families living in

poverty in that particular community. The data on the Northwest Suburban High School district shows that the number of poor students has continued to increase, yet there have been no changes to address this critical shift. 
As an educator, I would expect that students would go to their counselor for guidance in proper course selection to help them graduate. I found that this was not always the case. Some students did meet with their counselor, but a vast majority received advice and support from other staff members. The counselors whom I have worked with are amazing at their jobs but often, their caseload makes it almost impossible to meet with every student regularly. Participants identified having a trusted adult, as am important reason for their success during the high school experience. This is why meeting regularly with a counselor would be beneficial to students, as this would allow them to make a connection between their definition of academic success and the courses they still need to graduate. I found that participants did not make a direct connection between their idea of success and academic success. Moreover, they were happy with their vision of success, which they all believed they achieved. They were not concerned with other people's definitions of success, definitions that often directly related to academic success. I understood where they were coming from because I had been through the same experiences. For many of them, graduating high school was a real success in their eyes and their family's eyes.

Every one of the participants believed that they were successful in their high school careers and receiving a high school diploma validated that belief. Not only did this piece of paper mean that they had successfully completed all state-required coursework required to receive a high school diploma, but also they now could continue their education. In their eyes, in much the same way I had viewed it, they had completed something that few, if any, members of their family had been able to achieve. Participants also stated that they could have done better to meet the definition of academic success but their family dynamics required them to do other things to help out. All of the seventeen participants described supportive and friendly faculty 
and staff as being relevant to them during the time in high school. Each participant was also successful because they had a trusted adult to talk to, someone who supported them during their educational quest. Making these students feel welcome and valued was a critical event that students looked forward to each day. These simple interactions meant more to them than receiving a good grade because there were no expectations at home, not because parents did not care, but rather because they had not been in their children's shoes. Staff members showed them the steps, helping them achieve academic success as well as shaping their future goals and plans. As many participants stated, growing up they often acted as interpreters for their parents because of the language barrier that existed. Among other inadequacies, language and cultural barriers within the educational system of the United States keep Latin@ families from being able to fully participate in their children's education. The socioeconomic status (SES) of many of these students requires their parents to concentrate on providing for their families, sometimes working two jobs, thus being unable to attend many school functions. The parent's English language proficiency may keep them from coming to the school as well and may prevent them from being advocates for their children. In such cases, the parents of these children miss out on the opportunity to help them succeed not because of their own doing but because of the lack of bilingual support staff in schools. This is not a fault of the parents because many Latin@ parents are there for their children in whatever way they can be. Like many parents today, my mother worked two jobs and required me to help raise my younger brothers and sister. She was doing the best she could, and thanks to the trusted adults I had at school, I was ultimately able to get out of the one-bedroom apartment where seven individuals lived.

During their high school experience, many participants viewed the diversity of students and inclusion of everyone in the schools as generally positive. They felt accepted and knew that 
there were others like them trying to succeed. However, participants from schools with a smaller Black and Latin@ student population felt that they were "just there," and that the schools did not want to do too much for them. As long as they followed the rules, they were okay. However, they felt that their experience was almost sink or swim. The fact that Latin@s in the district still feel this way, to me, indicates that the schools have not adjusted to their student population. According to the Illinois State report card during the last five years, the district has shown a $4 \%$ increase in its Latin@ population, while its white population had gone down from 54\% in 2014 to its current $46 \%$ in 2018 . It may be time to look at these trends and change as other districts have done when they face similar changes in student demographics.

According to Wright (2015), teachers of color tend to have a more positive perception of students of color, both academically and behaviorally, than other teachers do. A recent study found that African American teachers are less likely than white teachers to perceive African American students' behavior as disruptive. This, I believe, also holds for Latin@ teachers because when I was in charge of our school's Latin@ support group, I had a membership number of well over 65 participants. Students would seek me out because they knew I cared about them and would steer them in the right direction. In the time that I have been at the school, I have seen a few new staff members who represent our changing demographics. At the administrative level, I see even fewer minorities at the district level as well as at the current school where I work. According to the 2018 Illinois State report card, the number of white students stands at $32.6 \%$ while our Hispanic population has increased to $31.3 \%$ and African American have increased to $11.9 \%$. Illinois State report card indicates the percentage of white teachers has remained at $88 \%$ and underrepresented groups have been kept at a constant rate. Latin@ teachers over that period have stayed at a flat $6 \%$, and until recently, just about all the principals 
within the district had been white. District administrators have also reflected this trend as I could only find one Latin@ administrator at the administrative building.

Participants who I interviewed were successful, but instead of having various support systems specifically aimed at helping them overcome the challenges they faced in and out of school, they just had to depend on trusted adults. In other words, they were part of a student body that was primarily made up of white students, and they were required to "just go with the flow" if they wanted to be part of the schools' culture. The minimal amount of educational opportunities they had access to is something that can and should be remedied, as many participants stated how having more contact helped them achieve more. Project Achieve was brought up by numerous former students, and expanding the program to include all Latin@ students would only benefit the students and district in the end. This may cost more, but if we as educators are here for all students and the Latin@ population has increased while the white population has dipped, it would make sense to better accommodate the students whom you serve equally. An effective education system must take into account all the possible differences that affect all students' learning and what could keep them from being successful.

While I was surprised by the infrequency with which participants claimed to have met with guidance counselors, I still assumed that the successful participants were those who were able to meet with their counselors regularly. However, the successful Latin@ students did not meet with their counselors as much as I would have expected. The participant's narratives showed that a substantial portion of them only met with their counselors a minimum number of times. As long as they were passing their classes, they were only able to get that minimum number of visits with their counselors. Perhaps this was because of a lack of parental presence at school due to trust in the educational system or their parents' educational level. I am not sure 
why some participants met more with their counselors than others did, but I learned that there is no protocol for meeting with students. I know that in recent years, each of the five Northwest Suburban High Schools has hired Spanish speaking counselors, but parents still do not seem to attend school functions, especially if they are Spanish speakers. I know that from my mother's point of view, she would always say that the administrators were going to speak in English, and she would not be able to keep up with what they were saying. Even after more than 25 years, the number of bilingual, Latin@ administrators has not changed, and this is something that does not benefit those schools that have high percentages of Latin@ students in their student body. Having someone who can speak to them in Spanish would bring more parents to school functions and informational meetings, as they would be able to understand and express themselves.

Participants did not explain why they met with their counselors as little as they did. I could not find any statement that said why they did not meet with them more than a few times during their time in school. This was interesting because many participants stated that they only met with their counselors once a year to pick classes, and that was it as far as getting help from a person whose job it is to be on top of their students' progress. The hiring of more personnel would help remedy this, as most counselors have set numbers of students they have to advise each year. I believe that hiring more Latin@ counselors would help more students because they would have fewer students to keep track of and would allow them to see more of those who are just getting by. I believe that it is the school's responsibility to help students from underrepresented groups establish social networks that help them feel more at home with the rest of the students. Student participants did not have family members who understood the importance of planning for college, as they may not have done it themselves. This is why it is 
essential to have counselors help build these networks for students to participate in and gain exposure that they will bring back home and explain to their parents. Project Achieve exposed the participants to college prep activities, college tours, and expected them to meet requirements to continue to be in the program.

Like other forms of capital, social capital can facilitate outcomes that otherwise would not be possible because students are part of a social class that participates in various social functions. Latin@s make up a large portion of the student population of the five Northwest Suburban High Schools and the information that they learn at school is added to their understanding of the educational process. The understanding will now become part of that families' cultural capital and will be passed on to other family members and relatives. While Latin@ students might be part of the social structure at school, the assumption that they possess the same social capital as other students is inaccurate. If students are not exposed to equal educational opportunities in school, they may not gain the requisite social capital and understanding necessary to navigate school beyond high school. I believe schools are ignoring this basic idea when it comes to Latin@ students. Literacy level, as was explained earlier, we're five years behind those who were not classified as being of lower social, economic status. At school, they are behind, and then at home, they do not have someone who can help them with their homework because many parents did not have the same schooling as their children. Additionally, students speaking two languages, which many of the participants used before, during, and then after the interviews. This was something that made them feel comfortable and came naturally to them because they did that with their parents. Students do that all the time in class and with their friends, as many approach speaking English or in Spanish during my Heritage speaker courses, which was part of our classes' social makeup. In much the same way 
that cultural capital helps many white students understand and meet expectations, social capital is also connected to academic success. A general lack of social capital places Latin@ students at a disadvantage because they may not be members of the networks that make the schools function. Coleman (1988) writes about networks that, as families, work on behalf of the members of the network to help all members reach their goals. In many ways, those who possess social capital just by belonging to a social class also possess support groups who help them in their education and academic success. Some of the participants met with their counselors, but generally, they met only a few times to select the following year's classes. Other participants met with their counselors more than the minimal number of times and they stated that this was beneficial. Their counselors were able to answer their questions, and as a result, they felt more prepared and better understood the importance of their education.

All participants received information that helped them continue their education but not always from their school counselors. The information came from a variety of sources. Some schools offered more support connected to heritage and culture in the form of clubs, support groups, and classes for heritage speakers. As Latin@s, the participants who experienced this kind of support were thankful, claiming that it made a difference. If it had not been for my counselors and one in particular, I know I would not be in the position that I am in right now. The participants knew from whom the specific support they received that helped them to achieve their vision of success had come.

However, again, when we write about Latin@students, we need to realize that Latin@s are not all the same. Latin@s do not all come from the same cultural backgrounds or share the same traditions and beliefs. While many speak Spanish, some do not, which can complicate how we classify some of the students. This, along with other complex issues, makes it difficult to 
define the word "Latin@." Those who identify as Latin@ come from different countries, have different cultural traditions, and practice different customs. Each Latin@ is different when it comes to their cultural background, but most individuals look at the Latin@ population as a whole and not at how different it can be from one individual to another. For instance, I was raised in Mexico up until the age of seven, when my parents finally had enough money to pay for my younger brother and me to come to the United States. When it came to education, I had to learn on the go. From an early age, I also helped out as much as I could around the house because my mother worked two jobs. When I lived in Mexico, I was going to school at the same time as I helped my grandparents with the crops during the harvest. In the United States, my cultural capital increased and defines who I am today, as much as it continues to represent all Latin@s.

Research has been conducted and has identified factors that many Latin@ students share when it comes to lack of educational success. The literature explained how five factors affected academic success among Latin@ students. The five factors that were identified are, in many cases, out of the control of Latin@s and they are interconnected. I believe that the most important factor that could be improved with the help of a changing educational system is socioeconomic status, which provides the advantages that having money brings. The parents of many Latin@ students in the district do not have a high socioeconomic status and have to work to provide the essential necessities for their children. In addition to stress created by living with limited means, the cultural differences that exist among and between Latin@s and the dominant school culture results in acculturative stress. As a result of the previously mentioned factors, Latin@ students may lack exposure to learning opportunities that other students have access to when it comes to education. Latin@ students are looking for a way to balance the many factors 
that can keep them from being successful. Understanding what others did to have success is essential to helping more Latin@s not only to graduate from high school, but also to have the opportunity to diminish the impact of the five factors that I identified as affecting academic success among Latin@s.

\section{Limitations}

This study had several limitations, which affected the analysis of the findings. One major limitation was the small number of participants with whom I was able to conduct interviews because it created a small sample size from which to obtain answers to the questions related to the district as a whole. I was not able to develop personal connections with all of the participants, as I did with those who responded from my school. A second limitation of the study was that I had to wait until the students had graduated to contact them and arrange an interview. If I had been able to reach students while they were in school, I could have arranged for more interviews with other former students. The more interviews completed, the more extensive the representation that I would have of the district. I now see that the study was also limited because it required interpretation of each of the responses to each of the questions. I bring a different perspective than someone else may because of my connection to the experiences having had to experience them myself. Others may read the participants' responses differently because they do not have the background that I do and may come up with different interpretations due to their lack of personal understanding. Even after more than twenty-five

years, this study has shown me that students who are members of non-majority groups in schools still need additional support.

Lastly, the student participants in this study were identified by high school counselors, who knew them and had worked with them. I wanted to focus on students who succeeded 
because so much of the literature that I researched was focused on those who did not have success. In doing this research, I believe that I am filling a gap by focusing on real student success. If the information they provided can help just one more student, than that will mean it was worth it.

\section{Recommendations}

Much of the research conducted on Latin@ students and their academic success has shown that Latin@s are at a higher risk for failing than their white counterparts. Knowing how to help these students can help more Latin@s continue their education, regardless of the obstacles they have to face. The resilience described by the participants in this study showed that they had to overcome the same challenges that others also had to overcome. While the findings cannot be generalized to other districts that may not have as diverse a student body as the district that was studied, they do have many implications for programs, policy, and professional practice. By helping students who come from a similar background, we can ensure that they will have the opportunity to get a degree and employment that can change the entire family. The results of the research study provided readers insight into many factors that affected students during high school that may not have been considered previously. First, this study shows that students may need more assistance than school staff might think and since they assume that they are doing fine may keep them from receiving additional support. Those who participated in the study believed they were successful during their high school careers because they were able to graduate and now had the opportunity to continue their education. Second, a large number of the participants were identified based on their test scores even before reaching high school and took part in Project Achieve. As such, these students were exposed to educational opportunities that set them apart from most other students. This, of course, was an advantage, and, as many participants 
stated, it was one of the main reasons why they believed they were successful once they

graduated from high school. Based on their responses, the participants knew they were lucky to be part of such a program. Other participants, who were not part of Project Achieve, stated that their trusted adult was a big reason why they were successful.

Next, it is essential to recognize that Latin@ students are not all the same, even if they all speak Spanish. This is something that emerged from my research as well as the similarities that I thought most students still felt as I did when it came to the educational process. Understanding their cultural differences can help educators reach more students as well as parents. Many Latin@ students face challenges that other students may not. Sometimes these challenges are related to cultural differences, and other times, they are tied to extra-educational responsibilities, such as working before and after school to help their families. This is important because this is sometimes the reason why a student may fail to turn in homework on time or may struggle to stay awake during class on a given day. Along the same lines, when the parents of these students do not come to open houses, this does not represent a lack of commitment to help their children succeed. For many reasons, some parents feel out of place in such an environment. Finally, this study demonstrates that, with a support system, the participants were able to achieve success and graduate from high school. This shows that students at any of the Northwest suburban schools had quite a number of trusted adults who would guide them.

\section{Future Studies}

In the future, I would like to conduct an entire school survey of all the Latin@s who graduated, and I would like to do so at each of the high schools that make up the Northwest suburban school district. Conducting an exit survey, one specifically created for the Latin@ population would provide vital information to identify areas of need, particularly as 
demographics change from year to year. In the surveys, students would be asked to measure how much support they received and identify what else could be done to help others. Graduating students would also be asked about the support given to them by teachers and administrators to get qualitative data that can be used quickly and effectively to bring about change within the district. This is important because understanding the educational trajectory of Latin@ students is extremely important if we are going to help more continue with their educations. The more students who succeed, the lower the dropout rate will be, and the better-prepared students will be. This information could be used by administrators, teachers, counselors, and others who work with students daily and help increase the number of successful students.

I would also like to examine a possible connection between a student's grades and the amount of contact time the student shares with a trusted adult. If there is, in fact, a positive correlation between grades and contact time with a trusted adult, then schools can use that information to address student needs sooner rather than later. Moreover, when students feel that their needs are not being met, they could voice their opinion to a trusted adult who could help change things for the better. This area of future study is especially important in light of my current findings, which showed that some students had more support than others, and those who had more seemed to be better prepared for college life.

\section{Conclusion}

Before the start of this research study, little was known about the experiences of former Latin@ high school students within the district. The results of this study shed light on the participants' perception of the factors that aided them in obtaining support during their high school years. One of my primary goals for this research study was to give a voice to the participants in regard to their experiences and views of the reality they experienced during that 
critical time in their lives. The information that I presented brings into question why the district has not changed along with its student demographics over the years and why does school staff continue to have an $87.9 \%$ white teacher classification, according to the Illinois State Report Card for the 2018 school year. Research has found that students learn when they are in the presence of minority teachers and administrators because they can relate to them. As students have entered school, they have been greeted by teachers who, more likely than not, are white women. That means many students will be continuing to see teachers who are a different gender and different skin colors than they are. Does it matter? Yes, according to a significant body of research: Students tend to benefit from having teachers who look like them, especially nonwhite students (Miller, 2018). Participants in the study talked about a caring adult whom they would seek out for advice and/or guidance. One can only imagine what the benefits would be if these participants were surrounded by more Latin@ teachers and administrators who understood from where these students were coming. If this was part of the school environment, then there were caring relationships and high expectations for the students. I know that at the school that I have been teaching for the past twenty years, there are amazing teachers who go beyond their role to help create a caring relationship and who have high expectations for their students. This is important because, as Gonzalez and Padilla (1997) found, a supportive academic environment and a sense of belonging at school were significant predictors of resilience. Increasing the number of staff members who represent the student body of that school can create a sense of belonging.

I found that the struggles I faced during high school are still evident in the battles of students today. Unlike those students who have friends and family members with significant educational experience, many Latin@ students continue to have questions about how to get from 
high school to college, and all too often, these questions go unanswered. While it may seem to some that everyone should know people with educational experience, I have found that this view lacks a fundamental understanding of the complexity of being a Latin@ student in our educational system. Many Latin@ students still do not understand the college process, and many do not know where to go to find the answers they need. The participants who took part in this study said their relationship with a trusted adult helped them answer their questions about the process of continuing their education.

Without a doubt, investing in student support systems helps students follow a path that will lead them to college and potentially out of their SES, as increased education has been proven to increase earning potential over a lifetime. As I have mentioned, I would never be in the position that I am if it were not for the trusted adults who saw something in me and helped me navigate the twisting and winding road that is our educational system for underrepresented students. Various support programs contributed not only to my academic success, but also to the positive academic experiences of many other students. For that reason, schools need to focus on the factors that contribute to the success of Latin@ students, and they must help those students who are falling behind, not because they are not trying, but because participants do not yet know how they can do better. Making connections with trusted adults, who kept them focused on their graduation, helped the participants. Participants were also part of Project Achieve that introduced them to college experiences in the form of college visits and other leadership building activities. Their ability to achieve success can help others when others implement the strategies used by successful Latin@ students. After conducting my research, I know that I am better prepared to participate in the creation and the design of support programs for at-risk Latin@ students. I believe that each school must do a better job of getting Latin@ parents involved in each school. 
The school district must look at the change in demographics and investigate the importance of hiring more teachers who represent the students they teach. Research has shown that, these students often only have these individuals as the only role models they can look up to. The district must also see that there is a need to put Latin@ administrators in each of the schools that have a large number of Latin@ students. Parents of these students will feel welcomed, just by having an administrator they can talk to and not a secretary who is interpreting for them. The success of students has always been a driving force for me because I would not be in the position that I am in today, if it were not for those who kept me reaching for more. I know that I can bring about change when it comes to assisting Latin@ students and filling the gaps that exist within the district. In the almost 21 years that I have been teaching, I have helped countless Latin@ students continue their education. I will seek out opportunities that will allow me to help a more significant number of students and bridge the gap that exists among Latin@ parents and their childrens' schools. 


\section{REFERENCES}

Abrego, L. J., \& Gonzales, R. G. (2010). Blocked paths, uncertain futures: The postsecondary education and labor market prospects of undocumented Latin@s youths. Journal of Education for Students Placed at Risk, $15,144-157$.

Alliance for Excellent Education, - The High Cost of High School Dropouts: What the Nation Pays for Inadequate High Schools, ॥ (Washington, DC: Author, 2008)

Adelman, H. S., \& Taylor, L. (2015, November 20). Immigrant Children and Youth in the USA: Facilitating Equity of Opportunity at School. Retrieved from https://www.mdpi.com/2227-7102/5/4/323/htm

American Psychological Association, Task Force on Socioeconomic Status (2007). Report of the APA Task Force on Socioeconomic Status. Washington, DC: American Psychological Association.

American Psychological Association, Education and Socioeconomic Status (2017). Retrieved from https://www.apa.org/pi/ses/resources/publications/education

Anastasi, A., Meade, M.J., and Schneider, A.A. (1960). The validation of a biographical inventory as a predictor of college success. College Entrance Examination Board: New York

August, D., \& Hakuta, K. (Eds.). (1997). Improving schooling for language-minority children: A research agenda. Washington, DC: National Academy Press. 
Balls-Organista, P. B., Organista, K. C., \& Kurasaki, K. (2003). The relation between acculturation and ethnic minority mental health. In. K. M. Chun, P. Balls Organista, and G. Marin (Eds.), Acculturation: Advances in theory, measurement, and applied research (pp. 139-161). Washington, DC: American Psychological Association.

Biemiller, A. (2006). Vocabulary development and instruction: A prerequisite for school learning. In D.K. Dickinson \& S. B. Neuman (Eds.), Handbook of early literacy research. New York: Guilford Press.

Berry, J. W. (2003). Conceptual approaches to acculturation. In K. M. Chun, P. B. Organista, \& G. Marin (Eds.), Acculturation: Advances in theory, measurement and applied research (pp. 17-37), Washington, DC: American Psychological Association.

Berry, J. W. (2005). Acculturation: Living successfully in two cultures. International Journal of Intercultural Relations, 29, 697-712.

Berry, J. W. (2006). Acculturative stress. In Wong, P. T. P. \& Wong, L. C. J. (Eds.) Handbook of Multicultural Perspectives on Stress and Coping. (pp. 287-298). New York: Springer.

Bohon, S. A., Johnson, M.K.,\& Gorman, B. K. (2006). College aspirations and expectations among Latin@s adolescents in the United States. Social Problems, 53, 207-225.

Bourdieu, Pierre (1984), Distinction: A Social Critique of the Judgment of Taste. Cambridge, MA: Harvard University Press.

Bumbaugh, D. E., 2009. The forgotten children in affluent America. In D.S. Eitzen and K. Eitzen Smith (Eds) Experiencing poverty: voices from the bottom, second edition Boston: Allyn \& Bacon. 
Bureau of Labor Statistics. (2018, March 27). Unemployment rates and earnings by educational attainment, 2017. U.S. Bureau of Labor Statistics. Retrieved from https://www.bls.gov/emp/chart-unemployment-earnings-education.htm

Bureau of Labor Statistics. (2018, April 26). College Enrollment and Work Activity of Recent High School and College Graduates Summary, 2018. U.S. Bureau of Labor Statistics. Retrieved from https://www.bls.gov/news.release/hsgec.nr0.htm

Cabrera, P. D., Swail, W. S. , \& Lee, J. (2000). National Education Longitudinal Study (NELS). U.S. Dept. of Education, National Center for Education Statistics. National education longitudinal study: Base year through fourth follow-up, 1988-2000 [Computer file]. ICPSR version. Washington, DC: U.S. Dept. of Education, National Center for Education Statistics [producer], 2002. Ann Arbor, MI: Inter-university Consortium for Political and Social Research.

Campbell, F. A., \& Ramey, C.T. (1994). Effects of early intervention on intellectual and academic achievement: A follow-up study of children from low-income families. Child Development, 65, 684-698.

Clandinin, D. (2013). Engaging in Narrative Inquiry (Developing Qualitative Inquiry) 1st Edition. New York, NY: Left Coast Press.

Cohen, M. Z., Kahn, D. L., and Steeves, R. H. (2000). Hermeneutic Phenomenological Research: A Practical Guide for Nurse Researchers. Thousand Oaks, CA: Sage.

Coleman, J. S. (1988). Social capital in the creation of human capital. American Journal of Sociology, 94 (Suppl.), 95-120.

College Board. (2011a). AP: Getting College Credit. Retrieved February 13, 2016, from http://www.collegeboard.com/student/testing/ap/exgrd_get.html 
Concha Delgado Gaitan (2012) Culture, Literacy, and Power In Family-Community-SchoolRelationships, Theory Into Practice, 51:4, 305-311

Contreras, F., Regade, A., Lee, J., \& McGuire, K. (2011). The college completion agenda: Research and context brief: Latin@s edition. Retrieved from the College Board website:http://media.collegeboard.com/digitalServices/public/pdf/rd/context_brief_Latin @s_2011.pdf

Creswell, J. W. (1998). Qualitative Inquiry and Research Design: Choosing Among Five Traditions. Thousand Oaks,California, Sage Publications.

Creswell, J. W. (2005). Educational research: Planning, conducting, and evaluating quantitative and qualitative research (2nd Ed.). Columbus, Ohio: Pearson Merrill Prentice Hall.

Creswell, J. W. (2007). Qualitative inquiry and research design. Choosing among five approaches. Thousand Oaks, CA: Sage.

Creswell, J. W. (2013). Qualitative inquiry and research design: Choosing among five approaches (3rd ed.). Thousand Oaks, CA: Sage.

Devore, V. (2011).Census data reveals a dramatic population increase among minority groups. Pbs news hour. Retrieved April 3, 2011, from http://www.pbs.org/ newshour/extra/features/us/jan-june11/census_04-01.pdf

Eamon, Mary. Keegan. 2005. Social-demographic, school, neighborhood, and parenting influences on academic achievement of Latin@s young adolescents. Journal of Youth and Adolescenc, 34(2), 163-175. 
Ebbers, S. M., Denton C. A.. (2008). A root awakening: Vocabulary instruction for older students with reading difficulties. Learning Disabilities Research \& Practice. 23(2), 90102.

Fisher, M. (1998). Latin@s education status and prospects: State of Latin@s America 1998. Washington D.C.: National Council of La Raza.

Fry, R. (2010). Hispanics, high school dropouts, and the GED. Washington, DC: Pew Hispanic Center.

Gándara, P. \& Contreras, F. (2009). The Latino Education Crisis: The consequences of failed social policies. Cambridge, MA: Harvard University Press.

Gandara, P. (2010). The Latin@s education crisis. Educational leadership, 67 (5), 24-30.

Garcia Coll, C. T., Akiba, D., Palacios, N., Bailey, B., Silver, R.,DiMartino, L., Bailey, B. (2002). Parental involvement in children's education: Lessons from three immigrant groups. Parenting: Science and Practice, 2, 303-324.

Glesne, C. (1999). Becoming qualitative researchers: An introduction (2nd ed.). White Plains, NY: Longman.

Glesne, C. (2011). Becoming qualitative researchers: An introduction. (4th ed.). Boston, MA: Pearson.

Goldenberg, C., \& Coleman, R. (2010). Promoting academic achievement among English learners: A guide to the research. Thousand Oaks, CA: Sage.

Gonzales, N., Cauce, A. M., Friedman, R. J., \& Mason, C. (1996). Family, peer, and neighborhood influences on academic achievement among African-American adolescents: One year, prospective effects. American Journal of Neighborhood Psychology, 24(3), 365-387. 
Gonzalez, R., \& Padilla, A. M. (1997). The academic resilience of Mexican-American high school students. Hispanic Journal of Behavioral Sciences, 19, 301-317.

Heaton, D. (2013). Resilience and Resistance in Academically Successful Latino/a Students (Doctoral Dissertation, Utah State University, Logan, Utah). Retrieved from https://digitalcommons.usu.edu/etd/1490/

Heinrich, K. T. (1995). Doctoral Advisement Relationships Between Women: On Friendship and Betrayal. Journal of Higher Education, 66(4), 447 - 469.

Hedrick, W. B., Harmon, J. M., Wood, K. (2008). Prominent content vocabulary strategies and what secondary preservice teachers think about them. Reading Psychology, 29: 443-470.

Henderson, N., \& Milstein, M. M. (2003). Resiliency in schools: Making it happen for students and educators. Thousand Oaks, CA: Corwin.

Hess, R., \& Holloway S. (1984). "Family and school as educational institutions," in Review of Child Development Research Vol. 7 ed. Parke R. D., editor. (Chicago: University of Chicago Press; ) 179-222

Hill, N. E. \& Torres, K. (2010). Negotiating the American dream: The paradox of aspirations and achievement among Latin@s students and engagement between their families and schools. Journal of Social Issues, 66 (1), 95-112.

Hollins, E.R., King, J.E., \& Hayman, W.C. (Eds.). (1994). Teaching Diverse Populations: Formulating a Knowledge Base. Albany: State University of New York Press.

Hoover-Dempsey, K. V., Walker, J. M. T., \& Sandler, H. M. (2005). Parents' motivations for involvement in their children's education. In E. N. Patrikakou, R. P. Weisberg, S. Redding, and H. J. Walberg, (Eds.), School-Family Partnerships for Children's Success (pp. 40-56). NY: Teachers College Press. 
Illinois State Board of Education. (2017). Illinois Report Card Retrieved from https://www.illinoisreportcard.com/District.aspx?DistrictID=05016211017

Jencks, C. \& M. Philips (Eds.). (1998). The Black-White Test Score Gap. Washington, DC: Brookings Institution Press.

Jensen, E. (2013). How Poverty Affects Classroom Engagement. Educational Leadership

King, J. (Ed.) (2005) Black education: A transformative research and action agenda for the new century. Mahwah, NJ: Lawrence Erlbaum Associates

Kao, Grace, and Marta Tienda (1995): “Optimism and achievement: the educational performance of immigrant youth,” Social Science Quarterly 76, 1: 1-19.

Lee, J., and Bowen, N. (2006). Parent involvement, cultural capital, and the achievement gap among elementary school children. American Educational Research Journal, 43, 193-218

Leonardo, Z. (2007). The war on schools: NCLB, nation creation, and the educational construction of whiteness. Race, Ethnicity, and Education, 10 (3), 261--278.

Lynn, M., Yosso, T. J., Solórzano, D. G., \& Parker, L. (2002). Critical race theory and education: Qualitative research in the new millennium. Qualitative Inquiry, 8 (1), 3-6.

Logan, John R., Brian J. Stults, and Reynolds Farley. 2004. Segregation of Minorities in the Metropolis: Two Decades of Change." Demography 41:1-22.

Madison, D. (2005). Critical ethnography as street performance: Reflection of home, race, murder, and justice. In N. K. Denzin \& Y. S. Lincoln (Eds.), The sage handbook of qualitative research (3rd ed.) (pp. 537-546). Thousand Oaks, CA: SAGE Publications.

Malabonga, V., Kenyon, D. M., Carlo, M., August, D., \& Louguit, M. (2008). Development of a cognate awareness measure for Spanish-speaking English language learners. Language Testing, 25 (4), 495-519. 
Massey, Douglas S., and Nancy A. Denton. 1993. American Apartheid: Segregation and the Making of the Underclass. Cambridge, MA: Harvard University Press.

Merriam, S.B., (1988). Case study research in education: a qualitative approach. San Francisco, CA: Jossey-Bass.

Merriam, S.B., (1998). Qualitative research and case study applications in education: revised and expanded from case study research in education. San Francisco, CA: Jossey-Bass.

Merriam, S. B. (2009).Qualitative research: A guide to design and implementation. San Francisco, CA: John Wiley \& Sons, Inc.

Mercy J. A., Steelman L. C. (1982). Familial influence on the intellectual attainment of children. Am. Social. Rev. 47 532-542.

Miles, M., \& Huberman, A.M. (1994). Qualitative data analysis. Thousand Oaks, CA: Sage.

Miller, C. C. (2018, September 10). Does Teacher Diversity Matter in Student Learning? Retrieved June 19, 2019, from https://www.nytimes.com/2018/09/10/upshot/teacherdiversity-effect-students-learning.html

Murnane, Richard, Rebecca Maynard, and James Ohls. 1981 “'Home Resources and Children's achievement."' Review of Economics and Statistics 63(3):369-77.

Moustakas, C. (1994). Phenomenological research methods. Thousand Oaks, CA: Sage. (n.d.). Retrieved January 11, 2016, from http://adc.d211.org/about-us-home/schools/ (n.d.). Retrieved February 2, 2016, from http://www.apa.org/pi/ses/resources/publications/factsheet-education.aspx National Center for Education Statistics.(2015). Fast Facts. Washington, DC. Retrieved from https://nces.ed.gov/fastfacts/display.asp?id=65 
Nuñez, A. (2009). Latino students' transitions to college: A social and intercultural capital perspective. Harvard Educational Review, 79(1), 22-48.

Pandey, A. (2013) What is the role of home language learning and maintenance in supporting successful outcomes in English language learning and literacy? In Young Dual Language Learners: A Guide for PreK - 3 Leaders (2014). Editor Karen N. Nemeth. Philadelphia, PA: Caslon Publishing.

Peterson, Ruth D., and Lauren J. Krivo. 2010. Divergent Social Worlds: Neighborhood Crime and the Racial-Spatial Divide. New York: Russell Sage.

Pignatelli, F., \& Pflaum, S. W. (Eds.) (1994). Experiencing diversity: toward educational equity. Thousand Oaks, CA: Corwin Press.

Prelow, H., \& Loukas, A. (2003). The role of resource, protective, and risk factors on academic participant's outcomes of economically disadvantaged Latin@s youth. Journal of Community Psychology, 31, 513-521.

Ramirez, A. (2003). Dismay and disappointment: Parental involvement of Latin@s immigrant parents. Urban Review (35), 92-110.

Reardon, S. F., Valentino, R. A., Kalogrides, D., Shores, K. A., \& Greenberg, E. H. (2013). Patterns and trends in racial academic achievement gaps among states, 1999-2011. Retrieved from https://cepa.stanford.edu/content/patterns-and-trends-racial-academicachievement-gaps-among-states-1999-2011

Reeves, R., \& Halikias, D. (2017, February 1). Race gaps in SAT scores highlight inequality and hinder upward mobility. Brookings. Retrieved from https://www.brookings.edu/research/race-gaps-in-sat-scores-highlight-inequality-andhinder-upward-mobility/ 
Richards, J.M.Jr., Holland, J.L., and Lutz, S.W. (1967). Predication of student accomplishment in college. Journal of Educational Psychology 58(6), 343-55.

Rodriguez-Valls, F. (2009). Cooperative bi-literacy: Parents, students, and teachers read to transform. English Teaching: Practice and Critique, 8(2), 114-136. Retrieved from http://education.waikato.ac.nz/research/journal/index.php?id=1

Romero, A. J., Carvajal, S. C., Valle, F., \& Orduña, M. (2007). Adolescent bicultural stress and its impact on mental well-being among Latin@s, Asian Americans \& European Americans. Journal of Community Psychology, 35, 519-534.

Romero A. J., Martínez D., Carvajal S. C. (2007). Bicultural stress and adolescent risk behaviors in a community sample of Latin@s and non-Latin@s European Americans. Ethnicity \& Health, 12, 443-463.

Rupley, W. H., \& Slough, S. (2010). Building prior knowledge and vocabulary in science in the intermediate grades: Creating hooks for learning. Literacy Research and Instruction, 49 (2), 99-112.

Sanders, P. (1982). Phenomenology: A New Way of Viewing Organizational Research. The Academy of Management Review, 7(3), 353 - 360.

Sanchez, R. (2013). Toward a greater understanding of Hispanic Undergraduate Retention at a Private Christian University Using Narrative Inquiry and Autoethnographic Methods. (Doctoral Dissertation). Retrieved from ProQuest Dissertations Publishing, 2016. (Accession No. 10125303)

Scholmerich, A., Leyendecker, B., Citlak, B., Caspar, U., \& Jakel, J. (2008). Assessment of migrant and minority children. Journal of Psychology, 216 (3), 187-194. 
Secada, W. G., Chavez-Chavez, R., Garcia, E., Munoz, C., Oakes, J., Santiago-Santiago, I., \& Salvin, R. (1998). No more excuses: The final report of Latin@ s/a dropout project. Madison, WI: Wisconsin University, Department of Curriculum and Instruction.

Seidman, I. E. (2005). Interviewing as Qualitative Research: A Guide for Researchers in Education and Social Science, New York, NY: Teachers College Press.

Seidman, A. (2005). Minority student retention: Resources for practitioners. In Minority retention: What works? ed. G. H. Gaither, 7-24. San Francisco, CA: Jossey-Bass

Smokowski, P.R,\& Bacallao, M .L.(2007). Acculturation internalizing mental health symptoms, and self-esteem: Cultural experiences of Latin@s adolescents in North Carolina. Child Psychiatry \& Human Development, 37, 273-292.

Solórzano, D. \& Yosso, T. (2001) Critical Race Theory and LatCrit Theory and Method: Counter storytelling Chicana and Chicano graduate school experiences. International Journal of Qualitative Studies in Education, 14(40), 471-495

Stanovich, K.E. (1986). Matthew effects in reading: Some consequences of individual differences in the acquisition of literacy. Reading Research Quarterly, 21, 360-407.

The State of Teacher Diversity in American Education. (2015, August 31). Retrieved June 26, 2019, from https://eric.edu.gov/?id=ED563794

Stromquist, N. P. (2011). The educational experience of Hispanic immigrants in the United States: Integration through marginalization. Race, Ethnicity, and Education, 15(2), 195221. 
Sullivan, A. (2002). Bourdieu and education: How useful is Bourdieu's theory for researchers? Netherlands Journal of Social Sciences, 2002. [Accessed online at http://www.cls.ioe.ac.uk/librarymedia\%5Cdocuments\%5CBOURDIEU\%20NetherlandsJournal.pdf on 20th April 2016]

Tienken, C. (2019, March 04). Students' test scores tell us more about the community they live in than what they know. Retrieved March 17, 2019, from http://theconversation.com/students-test-scores-tell-us-more-about-the-community-theylive-in-than-what-they-know-77934

Tienda, Marta. 2008. "English Mastery and Academic Achievement." Paper presented at the annual meeting of the American Educational Researchers Association, March 2008, New York.

Umansky, I. M., \& Reardon, S. F. (2014). Reclassification patterns among Latin@s English learner students in bilingual, dual immersion, and English immersion classrooms. American Educational Research Journal, 51 (5), 879-912.

U.S. Census Bureau. (2011b). Statistical abstract of U.S. Table 225: Educational attainment by race and Hispanic origin.

U.S. Census Bureau.(2012). “ 2010 Census Shows Nation's Hispanic Population Grew Four Times Faster Than Total U.S. Population.”

Vacca, Richard T. "From Efficient Decoders to Strategic Readers." Educational Leadership, November 2002, p. 9.

Van Manen, M. (1990). Researching lived experience: Human science for an action sensitive pedagogy — New York: State University of New York Press. 
Villenas, S. \& Deyhle, D. (1999). Critical race theories and ethnographies challenging the stereotypes: Latin@s families, schooling, resilience, and resistance. Curriculum Inquiry, $29(4), 413-445$.

Wells, A. S., Fox, L., \& Cordova-Cobo, D. (2017, April 03). How Racially Diverse Schools and Classrooms Can Benefit All Students. Retrieved March 17, 2019, from https://tcf.org/content/report/how-racially-diverse-schools-and-classrooms-can-benefitall-students/?session $=1$

Wiersma, W. (1995). Research methods in education: An introduction. Needham Heights, MA. Allyn and Bacon.

Williams, T., Hakuta, K., Haertel, E., et al. (2007). Similar English learner students, different results: Why do some schools do better? A follow-up analysis, based on a large-scale survey of California elementary schools serving low-income and EL students. Mountain View, CA: EdSource.

Willingham, W.W. (1985) Success in college: The role of personal qualities and academic ability. New York: College Entrance Examination Board.

Wilkes, Rima, and John Iceland. 2004. "Hypersegregation in the Twenty-First Century." Demography 41:23-36.

Wright C. A (2015). Teachers' Perceptions of Students' Disruptive Behavior: The Effect of Racial Congruence and Consequences for School Suspension” (Santa Barbara, CA: University of California Department of Economics, 2015), available at https://aefpweb.org/sites/default/files/webform/41/Race\%20Match,\%20Disruptive\%20Be havior, \%20and\%20School\%20Suspension.pdf. 
Yosso, T. (2000). A critical race and LatCrit approach to media literacy: Chicana/o resistance to visual microagressions (Unpublished doctoral dissertation). University of California, Los Angeles

Yosso, T.J. (2005). Whose culture has capital? Race, Ethnicity, and Education, 8(1), pp. 69-91.

Yosso, T.J., \& Solórzano, D.G., (2006). Leaks in the Chicana and Chicano educational pipeline. Latino Policy and Issues, 8(13), 1-4.

Zwick, Rebbeca (2012). The Role of Admissions Test Scores, Socioeconomic Status, and High School Grades in Predicting College Achievement. Educational Testing Service, USA 


\section{APPENDIX A: RECRUITMENT EMAIL}

Dear

I am a doctoral student at Illinois State University. I am currently completing my dissertation with the help of Dr. Elizabeth Skinner in the College of Education. I am conducting a research study to examine student perception of the overall support provided Latin@ students during their high school experience. This study also seeks to identify additional student needs during high school, which I hope will facilitate the creation of further support systems for future students. I am inviting Latino/a graduates of a Northwest Suburban High School, who are 18 years or older, to participate in this study. Because you meet those criteria, I would like to invite your participation.

Participation will involve one audio-taped interview with me that will take place in a private location convenient to you. This interview will last approximately 45 - 60 minutes. During the meeting, questions will be asked regarding your educational experience while in high school. These questions will relate to your thoughts and experiences with the level of support your high school offered you during your high school career. Your answers to the questions will be kept confidential and at no time will your name be associated with your responses. The school district and your high school will not be identified either. In addition to the audio recording, I may also be taking notes, which will be descriptive and analytical in nature, intended to remind me of the context of our interview and/or any ideas that may occur to me throughout.

The possible benefit of your participation will be the sharing of experiences that may help future Latino/a students of similar backgrounds. There are minimal physical, psychological, or social 
risks to the participants in this study. Depending upon your high school experience, you may experience discomfort or an emotional response when recalling events from high school. Keep in mind that you may decline to respond to or omit; any question you do not feel comfortable answering.

Your participation is voluntary. If you would like to be a part of this research study, please respond to this recruitment e-mail and provide a telephone number and a good time when I may call you. If you are interested in being a participant and you reply to the email, I will call you within $1-2$ days to set up a convenient time for the interview.

Thank you very much for your time and interest in this study. Your opinions will be invaluable to the success of this research study.

Sincerely,

Octavio Rodriguez 


\section{APPENDIX B: INFORMED CONSENT}

Dear participants,

My name is Octavio Rodriguez; I am a doctoral student under the direction of Dr. Elizabeth Skinner in the College of Education at Illinois State University. I am conducting a research study to examine student perception of the overall support provided to Latino/a students during their high school experience.

I am inviting Latino/a graduates of a Northwest Suburban High School, who are 18 years or older, to participate in this study. Because you meet those criteria, I would like to invite your participation.

Participation in the research will involve one interview with me that will take place at a location convenient to you and last about 45-60 minutes. The interview will be audiotaped with your permission. In addition to the audio recording, I may also be taking notes, which will be descriptive and analytical, intended to remind me of the context of our interview and any ideas that may occur to me throughout. Please be aware that your participation in this study is entirely voluntary. You are not required to participate. If you choose not to participate or to withdraw from the study at any time, there will be no penalty. During the interview process, you may choose to omit any question that you do not feel comfortable answering. The results of the research study may be published, but all interviews will be kept entirely confidential, and your name will not be connected to results or used in any way. Your former high school and school district will not be named or identified. The goal of the study is to identify what helped you 
successfully complete your high school career. However, there may be no direct benefit to you. The possible benefit of your participation in the sharing of experiences that may help future Latino/a students of similar backgrounds. There are minimal physical, psychological, or social risks to the participants in this study, Depending upon your high school experience, you may experience discomfort or an emotional response when recalling events from high school Keep in mind that you may omit any question you do not feel comfortable answering. If you have any questions, please reply to this email or call me at (847) 340-6527, or Dr. Elizabeth Skinner at (773) 661-0838. If you have any questions about your rights as a subject/participant in this research, or if you feel you have been placed at risk, you may also contact the Research Ethics and Compliance Office at Illinois State University (309-438-2529 or rec@IllinoisState.edu).

Thank you for considering participating in this research study.

Sincerely,

Octavio Rodriguez

I give consent to participate in the above study.

Signature

Date

I give consent for my interview to be audiotaped.

Signature

Date 


\section{APPENDIX C: INTERVIEW QUESTIONS}

As a participant, you may choose to omit any of the following questions during the interview process.

School connection and support component:

1. How would you describe success in your own words?

2. Do you believe that you were successful during your high school career?

3. What positive and negative views or experiences stand out during your education in the American school you attended?

4. What type of experiences or relationships did you have with your teachers in the school you attended? Can you explain the role that your teachers played in developing their future academic choices?

5. During your high school career, how many times did you meet with a counselor? During these meetings, how often did you receive information that was important and helpful to you for continuing your education?

6. How often did the school provide current information about your individual academic progress, and how well did the school help you to understand and to practice strategies for academic success?

7. How informative and supportive were the counselors at your school, especially with regard to college entrance requirements (i.e., grade requirements, test preparation, the application process, and admissions practices)?

8. From your perspective, how supportive was the school of your heritage and cultural background? In what ways were your heritage and cultural background incorporated into the school's educational mission? 
9. What types of academic support did the school provide to assist with your continuing education? In your view, what kinds of academic support did the school lack?

10. In your experience, what effect did the academic and cultural support system at your school have on your academic success? 